Original Research Article

\title{
Implications of two different methods for analyzing total dietary fiber in foods for food composition databases
}

\author{
Katherine M. Phillips ${ }^{\mathrm{a}, *}$, David B. Haytowitz ${ }^{\mathrm{b}, 1}$, Pamela R. Pehrsson ${ }^{\mathrm{b}}$ \\ ${ }^{a}$ Biochemistry Department, Virginia Tech, Blacksburg, VA, USA \\ ${ }^{\mathrm{b}}$ United States Department of Agriculture, Agricultural Research Service, Nutrient Data Laboratory, Beltsville, MD, USA
}

\section{A R T I C L E I N F O}

\section{Keywords:}

Beans

Food analysis

Food composition

Dietary fiber

Analytical methods

Food composition databases

Legumes

Nutrition

Potatoes

Quality control

\begin{abstract}
A B S T R A C T
Since 1989, total dietary fiber values in USDA databases were determined by the enzymatic-gravimetric (EGF) method (AOAC 991.43), where "fiber" is the residue remaining after samples are subjected to enzymatic treatments mimicking digestion. In 2009 EGF was modified to recover additional non-digestible components (e.g., galacto/fructo-oligosaccharides, polydextrose, resistant starch) (AOAC 2009.01, 2011.25) (mEGF). Limited mEGF data and high cost create a need to identify suitable foods for analysis. USDA's National Food and Nutrient Analysis Program sampled suitable foods for analysis by EGF and mEGF. No detectable difference between EGF and mEGF was found in almonds, wheat bread, oatmeal cookies, tortilla chips, taco shells, kale, fast food French fries, or cooked dried pulses. mEGF exceeded EGF in uncooked dried pulses (5.4-10.5 g/100 g), raw potatoes $(13.7 \mathrm{~g} / 100 \mathrm{~g})$, and cooked plantains $(3.1 \mathrm{~g} / 100 \mathrm{~g})$, and slightly higher $(0.7-2.2 \mathrm{~g} / 100 \mathrm{~g})$ in hummus, canned refried beans, prepared wild rice mix, and frozen raspberry berries, concentrate, and puree. Statistical power was hindered by high analytical uncertainty, especially for mEGF (up to 33\% RSD), likely due to cumulative errors in the multiple steps comprising mEGF. mEGF analyses should focus on foods containing significant levels of fiber components not included in EGF, and reporting individual, particularly metabolically active, fiber components.
\end{abstract}

\section{Introduction}

The health benefits of dietary fiber consumption are widely accepted and include reduced risk of cancer and cardiovascular disease, and type 2 diabetes (Anderson et al., 2009; Dahl and Stewart, 2015; Jones, 2004; Kuijsten et al., 2015; Veronese et al., 2018). In 1975, the first Nutrition Facts panel required by U.S. Food and Drug Administration (FDA) regulations did not include fiber, but it was added in the Nutrition and Labeling and Education Act (1990), for which regulations became effective in May 1993 (U.S. Food and Drug Administration, 1994). The definition of "dietary fiber" has changed over the years. It was initially considered, and measured as, non-digestible carbohydrates and lignin that are intrinsic and intact in plants, primarily in the context of accounting for the portion of total carbohydrates determined by difference in proximate analyses, that were not digested and hence not contributing to energy intake (Cummings, 1976; Dai and Chau, 2017). From 1950 to approximately 1990, fiber was most commonly quantified as "crude fiber", defined as the portion of the food not soluble when boiled in dilute acid and dilute alkali, and mainly directed towards characterizing the composition of animal feed (Southgate, 1976). Research in the 1970s and 1980s suggested health benefits from particular forms of "fiber", such as sequestration of cholesterol by water-soluble fiber (e.g., pectins, beta-glucans), causing reduced intestinal absorption and lower blood cholesterol levels, consequently reducing the risk of coronary heart disease (Anderson, 1985; Cummings, 1976; Story et al., 1979). Thus, methodology to measure dietary fiber in foods was developed to mimic physiological digestion and allow for separation of soluble and insoluble fiber (Asp et al., 1983; Baker et al., 1979; Southgate, 1976; Theander and James, 1979). In 1985 the Association of Official Analytical Chemists (AOAC) adopted an enzymatic-gravimetric method, in which samples are subjected to serial digestion with amylase, amyloglucosidase, and protease, followed by isolation and gravimetric measurement of the residue as fiber (EGF). This method was first accepted in 1994 by the U.S. Food and Drug Administration (FDA) for food labeling (U.S. Food and Drug Administration, 1994). This approach, with minor variations [Official methods 991.43 and

\footnotetext{
This paper was originally submitted as an oral presentation at the 40th National Nutrient Databank Conference held from July 23-25, 2018, in Minneapolis, Minnesota, USA

* Corresponding author at: Biochemistry Department (0308), Virginia Tech, Blacksburg, VA, 24061, USA.

E-mail address: kmpvpi@vt.edu (K.M. Phillips).

${ }^{1}$ Retired.
} 
985.29 (AOAC, 2005a,b)] has been the standard through today and is accepted by the Food and Drug Administration (FDA) for food labeling purposes (Code of Federal Regulations, 2018).

Meanwhile research on dietary fiber and health outcomes continued, and the definition of "dietary fiber" expanded to address intrinsic fiber versus components added as functional ingredients to enhance the fiber content of processed foods (Table 1) and to include endogenous starch resistant to digestive enzymes ("resistant starch") and non-digestible oligosaccharides. Resistant starch and non-digestible oligosaccharides are active in the gut but not included in EGF (Dai and Chau, 2017; de Menezes et al., 2013). A modification of the EGF method (mEGF) was developed by McCleary et al. (McCleary, 2010; McCleary et al., 2010, 2012, 2013), that includes non-digestible oligosaccharides and some forms of resistant starch by changes to the digestion steps and addition of HPLC analysis.

The definition of dietary fiber varies among different governing organizations, and for food labeling versus other (e.g., research and food composition database) purposes. Some of these differences are summarized in Table 1 (also see excellent discussions by Jones, 2014; Stephen et al., 2017; Zielinski et al., 2013). It is particularly notable that the U.S. Food and Drug Administration (FDA) currently makes it optional to include non-digestible oligosaccharides of 3-9 monomeric units in fiber declared on food labels (U.S. Food and Drug Administration, 2018), but the Codex Alimentarius Commission, a United Nations organization jointly run by the Food and Agriculture Organization (FAO) and World Health Organization (WHO) and which oversees harmonization of food standards, excludes these components (Zielinski et al., 2013), but it is left to each country whether or not to adopt or modify this definition. Therefore, dietary fiber determined gravimetrically is essentially defined by the methodology used to measure it, and dietary fiber intake and values reported in food composition databases and on food labels from various sources do not always represent the same group of chemical compounds (Stephen et al., 2013; Westenbrink et al., 2013; Zielinski et al., 2013). Changing definitions and values in food composition databases for dietary fiber for the same foods but determined by different methodology have consequences for research on intake of dietary fiber and health outcomes, dietary recommendations, and nutritional assessment of "adequacy". Food composition data underlie population intake estimates for dietary fiber in epidemiological studies (Ahuja et al., 2006, 2012; Champagne et al., 2019; Greenfield and Southgate, 2003; Pehrsson and Haytowitz, 2016). Thus, conclusions and dietary recommendations can be confounded by the source and method of determination of dietary fiber in foods, a lack of consistency among different data sources, and unawareness by users of the data in the basis for "dietary fiber" values and how they have changed over the years (Stephen et al., 2017; Westenbrink et al., 2013).

Historically, some value for "fiber" has been available for many foods for more than 100 years. As early as 1892, crude fiber was included in the Atwater table of composition data for 178 food items (Atwater and Woods, 1896). Data on fiber became widely distributed in searchable databases starting in approximately 1992 (Haytowitz and Klensin, 1994), including the USDA National Nutrient Database for Standard Reference (SR) (Ahuja et al., 2012). In the U.S., SR data are used in conjunction with the National Health and Nutrition Examination Survey (NHANES)/What we Eat in America (WWEIA; Centers for Disease Control and Prevention, 2007) (Ahuja et al., 2006, 2012; Bodner-Montville et al., 2006). USDA data also are incorporated into many secondary databases developed to estimate intake in feeding trials and epidemiological studies; for example, the Harvard University Food Composition Database used in the Health Professionals Follow-Up Study on dietary intake and health outcomes (Harvard T.H. Chan School of Public Health, 2018), the Nutrient Data System for Research (University of Minnesota Nutrition Coordinating Center, 2018), and the ESHA Food Processor Nutrition Analysis software (ESHA Research, Salem, OR). Yet, as discussed, dietary fiber is measured as a group of compounds, not chemically distinct components, and methods have changed over the years, even if the actual composition of the food has not. Table 2 summarizes the evolution of methodology underlying dietary fiber data in the USDA food composition databases over the years. Since 1997, USDA efforts in the National Food and Nutrient Analysis Program (NFNAP) have included statistical nationwide sampling and chemical analysis of foods to update and increase the quality of data in SR (Haytowitz et al., 2008; Haytowitz and Pehrsson, 2018). Through 2018 (SR release 28/Legacy SR) (Haytowitz et al., 2018; U.S. Department of Agriculture, 2019), very few foods have been analyzed for mEGF. Analysis of dietary fiber, and particularly mEGF, is labor intensive and costly (Salmas et al., 2017). It is therefore important to understand the degree of difference in dietary fiber content of various foods as measured by different currently accepted methods for U.S. food labeling and nutrition (EGF versus mEGF), so that resources can be effectively allocated for updating dietary fiber food composition data, and to alert users of the data to possible explanations for discrepancies in dietary fiber intake calculated with data generated by different methodology.

The goal of this study was to compare the EGF and mEGF content of select foods that were sampled as part of the NFNAP, expected to contain varying levels of total dietary fiber and different components of dietary fiber, estimation of the analytical uncertainty of the measurements, and to make recommendations for where to focus efforts on

Table 1

Current definition of "dietary fiber" according to different organizations.

\begin{tabular}{|c|c|}
\hline Organization (year) & Definition of dietary fiber \\
\hline \multirow{3}{*}{$\begin{array}{l}\text { National Academy of Sciences (Institute of } \\
\text { Medicine, 2001) }\end{array}$} & "Dietary Fiber": non-digestible carbohydrates and lignin that are intrinsic and intact in plants \\
\hline & "Added Fiber": isolated, non-digestible carbohydrates that have beneficial physiological effects in humans \\
\hline & "Total Dietary Fiber": Dietary fiber + Added Fiber (No distinction between "soluble" and "insoluble" dietary fiber) \\
\hline CODEX Alimentarius (2009) & $\begin{array}{l}\text { Carbohydrate (CHO) polymers with ten or more monomeric units, which are not hydrolyzed by the endogenous enzymes in } \\
\text { the small intestine (SI) of humans. Whether or not to include non-digestible carbohydrates with 3-9 monomeric units is left } \\
\text { up to national authorities (e.g., the Food and Drug Administration in U.S.) }\end{array}$ \\
\hline \multirow[t]{7}{*}{$\begin{array}{l}\text { U.S. Food and Drug Administration (FDA) (2016, } \\
\text { 2018) }\end{array}$} & $\begin{array}{l}\text { Residue isolated by Total, Soluble, and Insoluble Dietary Fiber in Foods, Enzymatic-Gravimetric Method, MES-TRIS Buffer } \\
\text { (AOAC 991.43) (AOAC, 2005a) or Total Dietary Fiber in foods - Enzymatic-Gravimetric Method (AOAC 985.29) (AOAC, } \\
\text { 2005b) }\end{array}$ \\
\hline & Starting in 2016: May include non-digestible carbohydrates of 3-9 monomeric units (e.g., as determined by Insoluble, \\
\hline & Soluble, and Total Dietary Fiber in Foods Enzymatic-Gravimetric-Liquid Chromatography (AOAC, 2011.25) (AOAC, 2011) \\
\hline & or Total Dietary Fiber in Foods Enzymatic-Gravimetric-Liquid Chromatographic Method (AOAC 2009.01) (AOAC, 2012). In \\
\hline & May 2016: Defined "added fiber" as non-digestible carbohydrates having beneficial physiological effects in humans (U.S. \\
\hline & $\begin{array}{l}\text { Food and Drug Administration, 2018) not endogenous to the food product. The components are: beta-glucan soluble fiber, } \\
\text { psyllium husk, cellulose, guar gum, pectin, locust bean gum, and hydroxypropylmethylcellulose }\end{array}$ \\
\hline & $\begin{array}{l}\text { In June 2018, expanded list to include } 8 \text { more components (U.S. Food and Drug Administration, 2018): mixed plant cell } \\
\text { wall fibers, arabinoxylan, alginate, inulin and inulin-type fructans, high amylose starch (resistant starch 2), galacto- } \\
\text { oligosaccharides, polydextrose, and resistant maltodextrin/dextrin. }\end{array}$ \\
\hline
\end{tabular}


Table 2

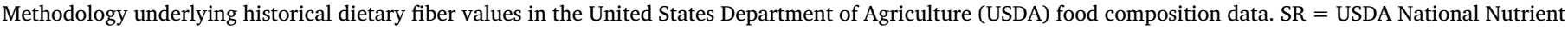
Database for Standard Reference (U.S. Department of Agriculture, 2016).

\begin{tabular}{|c|c|c|c|}
\hline Years & Fiber methodology & Measures & Disseminated in \\
\hline 1963-1990 & Crude fiber (Van Soest, 1978) & Cellulose and some lignins & $\begin{array}{l}\text { USDA Agriculture Handbook No. } 8 \text { (U.S. Department of } \\
\text { Agriculture, 1950- 1990U.S. Department of Agriculture } \\
\text { USDA's Agriculture, 1990U.S. Department of } \\
\text { Agriculture, 1950- 1990) }\end{array}$ \\
\hline 1989-1992 & $\begin{array}{l}\text { Neutral detergent fiber (Van Soest et al., 1991) } \\
\text { Crude fiber continued to be reported for foods } \\
\text { from earlier SR releases }\end{array}$ & $\begin{array}{l}\text { Most structural plant cell carbohydrates, including } \\
\text { cellulose, hemicellulose, and lignin (excludes pectin) }\end{array}$ & $\begin{array}{l}\text { USDA Agriculture Handbook No. } 8 \text { (U.S. Department of } \\
\text { Agriculture, 1950- 1990U.S. Department of Agriculture } \\
\text { USDA's Agriculture, 1990U.S. Department of } \\
\text { Agriculture, 1950- 1990) }\end{array}$ \\
\hline 1990-2018 & $\begin{array}{l}\text { Enzymatic-gravimetric total dietary fiber (AOAC } \\
\text { 985.29, 991.43) (AOAC } 2005 \mathrm{a}, \mathrm{b} \text { ) } \\
\text { Older data for crude fiber and neutral detergent } \\
\text { fiber was also reported for some foods. It was } \\
\text { removed with the release of SR11 in } 1996\end{array}$ & $\begin{array}{l}\text { Residue remaining after enzymatic treatments } \\
\text { simulating physiological digestion. Includes } \\
\text { cellulose, hemicellulose, lignin, pectin }\end{array}$ & $\begin{array}{l}\text { Standard Reference, releases 9-28 and Legacy SR (U.S. } \\
\text { Department of Agriculture, 2018) }\end{array}$ \\
\hline \multirow[t]{2}{*}{ 2019- } & $\begin{array}{l}\text { Modified enzymatic-gravimetric method } \\
\text { (McCleary method) (AOAC 2009.01 (AOAC, } \\
\text { 2012), 2011.25 (AOAC, 2011) }\end{array}$ & $\begin{array}{l}\text { As for enzymatic-gravimetric method, above, but } \\
\text { including non-digestible carbohydrates with three or } \\
\text { more monomeric units (intrinsic and added } \\
\text { components). } \\
\text { Possible components reported individually, for select } \\
\text { foods: } \\
\text { Beta-glucans } \\
\text { Resistant starch } \\
\text { Non-digestible oligosaccharides }\end{array}$ & $\begin{array}{l}\text { SR- Legacy (Haytowitz et al., 2018) } \\
\text { FoodData Central (U.S. Department of Agriculture, } \\
\text { 2019) }\end{array}$ \\
\hline & $\begin{array}{l}\text { Soluble and insoluble dietary fiber and individual } \\
\text { components reported for some foods. } \\
\text { Total Dietary Fiber values determined by the } \\
\text { enzymatic -gravimetric method will also be } \\
\text { included in FoodData Central (U.S. Department of } \\
\text { Agriculture, 2019) }\end{array}$ & Chitin & \\
\hline
\end{tabular}

dietary fiber analysis of foods and incorporation of data into food composition databases.

\section{Materials and methods}

\subsection{Food samples}

Commonly consumed foods that are considered good sources of dietary fiber but expected to contain different dietary fiber components (e.g., pectin, resistant starch, non-digestible oligosaccharides), were selected from among a range of foods samples procured for the NFNAP (Haytowitz and Pehrsson, 2018): legumes [dried chickpeas, peas, lentils (uncooked and cooked); canned refried beans, hummus); nuts and seeds (sunflower seeds, mixed nuts, almonds); fruits and vegetables (plantains, raspberries, kale); whole grain processed foods (wheat bread, taco shells, tortilla chips, oatmeal cookies, popcorn, prepared wild rice mix, French fries]. All samples were purchases at retail outlets, except the chickpeas, peas, and lentils (pre-cleaned) and raspberry products, which were received directly from producers, through the American Pulse Association (Moscow, ID) and National Processed Raspberry Council (Lynden, WA), respectively. Russet potatoes were purchased locally (Blacksburg, VA). Procedures for sampling and shipment of samples for the NFNAP have been previously reported (Trainer et al., 2010). The raspberry products were received frozen and stored frozen $\left(-60^{\circ} \mathrm{C}\right)$ prior to homogenization and subsampling for analysis. Sample information is summarized in Table 3, including ingredients listed on the label for packaged foods.

Samples requiring preparation were prepared immediately prior to homogenization. Dried pulses were boiled according to the parameters show in Table 3 for each sample. Baked potatoes (whole, with skin) were prepared by punching six approximately $0.5 \mathrm{~mm}$ wide by $2.5 \mathrm{~mm}$ deep holes around the potato, using a stainless steel pick, then baking in a conventional oven for $50 \mathrm{~min}$ at $218^{\circ} \mathrm{C}\left(425^{\circ} \mathrm{F}\right)$. The baked potatoes were allowed to cool at room temperature for $15 \mathrm{~min}$, then individually cut (unpeeled) into approximately $1.25 \mathrm{~cm}$ cubes, frozen in liquid nitrogen, and homogenized. Wild rice mix was prepared according to package instructions.

The uncooked dry pulses, almonds, and sunflower seeds were homogenized using a Vitamix 750 Professional Series blender with dry blade assembly (Vita-Mix Corp., Cleveland, $\mathrm{OH}$ ) resulting in a fine powder. The raspberry pureé and concentrate were thawed completely in the refrigerator $\left(2-4^{\circ} \mathrm{C}\right)$, then blended thoroughly with a whisk or spoon. All other foods were homogenized while frozen in liquid nitrogen (except for cooked peas, processed without liquid nitrogen), using a $6 \mathrm{~L}$ Robot Coupe Blixer ${ }^{\mathrm{TM}}$ industrial stainless steel food processor (Model BX6V; Robot Coupe, Ridgeland, MS). Subsamples of each homogenate were stored in $30-\mathrm{mL}$ or $60-\mathrm{mL}$ straight-sided glass jars with Teflon $^{\mathrm{TM}}$-lined screw caps. The homogenized foods were kept frozen in liquid nitrogen, and stored under residual nitrogen in the sealed jars, at $-60^{\circ} \mathrm{C}$ until analyzed.

\subsection{Control composites and standard reference materials}

In-house control composites (CC), developed for the NFNAP (Phillips et al., 2006) and commercially available standard reference materials (RM) having values for dietary fiber were analyzed with samples. NIST SRM ${ }^{\otimes} 2387$ Peanut Butter (with a reference value for EGF) and NIST SRM ${ }^{\circledR} 3233$ Fortified Breakfast Cereal (with reference values for EGF and $\mathrm{mEGF}$ ) were procured from the National Institute of Standards and Technology (NIST) (Gaithersburg, MD). CC included materials that had been previously analyzed with NFNAP food samples for EGF over a period of years ("Bread/Snack Food CC", "Cereal CC", "Starchy Vegetable II CC"), and a mixed vegetable composite ("Fiber Vegetable CC"), prepared specifically to include ingredients with different components that are part of mEGF. A description of the preparation and use of control materials for the NFNAP has been published previously (Phillips et al., 2006). Bread/Snack Food CC contained refrigerated biscuits (baked), whole wheat bread, white corn tortilla chips, corn muffins (prepared from mix), pound cake, oat bran muffins, and scones. Cereal CC was a multigrain toasted oat breakfast cereal. Starchy Vegetable II CC contained canned (drained) spinach, potatoes (without skin), refried beans, and vegetarian vegetable soup; baby food 


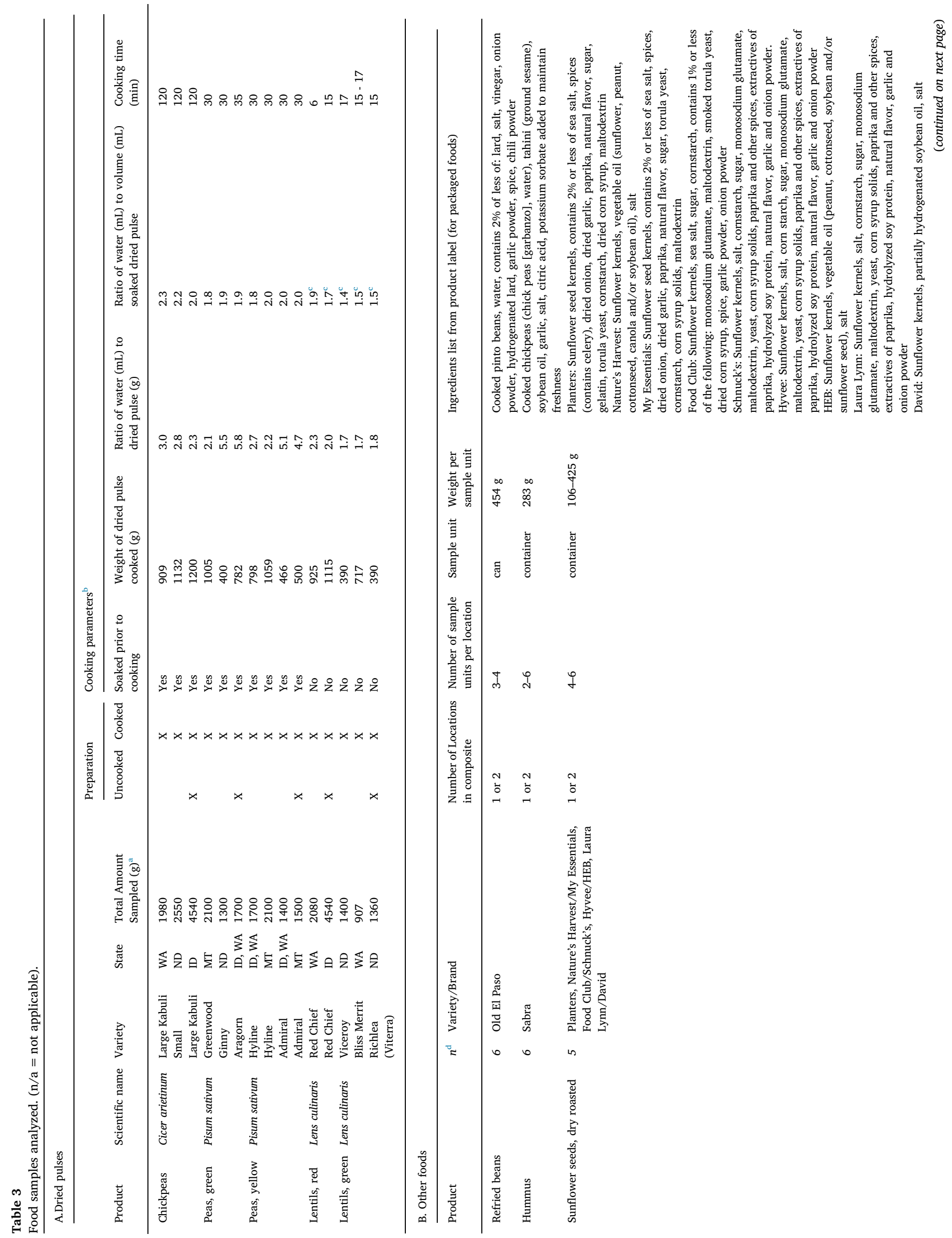




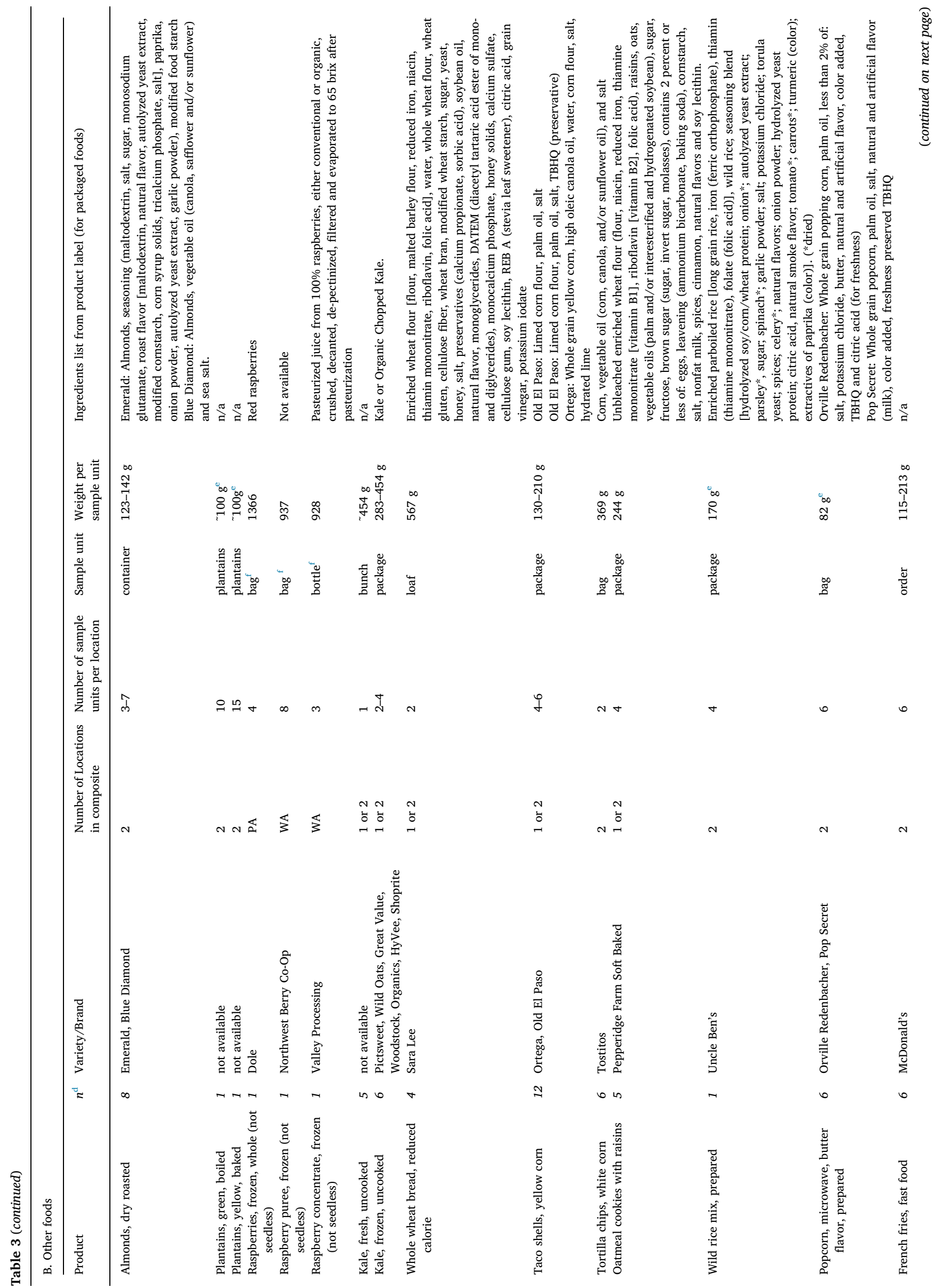


sweet potatoes and corn; non-iodized salt. Fiber Vegetable CC contained canned (drained) chickpeas, raw orange sweet potatoes (peeled), ripe bananas (peeled), baked russet potatoes (with skin), raw russet potatoes (without skin), raw kale (leaves only), and raw white onions (peeled).

\subsection{Analysis of dietary fiber}

EGF was measured by AOAC 991.43 (AOAC, 2005a) and mEGF by AOAC, 2011.25 (AOAC, 2011) or AOAC 2009.01 (AOAC, 2012), at two laboratories that had been previously qualified for analysis of dietary fiber by proficiency testing for the NFNAP (Haytowitz et al., 2008; Haytowitz and Pehrsson, 2018). Samples of CCs and RMs were included and analyzed with each batch of samples (Sections 2.2, 2.5) and enabled estimation of the contribution of lab-to-lab differences in measurement for each methodology. The frozen samples were shipped on dry ice via express overnight delivery and stored frozen before analysis. One laboratory stored samples at $-20^{\circ} \mathrm{C}$ and thawed to room temperature before analysis, and did not freeze-dry or grind. The other laboratory stored samples at $-70^{\circ} \mathrm{C}$, and did not freeze-dry or thaw before analysis.

\subsection{Proximate analyses}

Moisture, ash, total fat, protein, and starch were measured as part of the NFNAP, using standard methods and quality control measures. Methods and results are reported as supplementary material, to provide information on proximate composition.

\subsection{Quality control}

The food samples were grouped for EGF and mEGF analysis in batches, and a matrix-matched CC and/or RM sample (Bread/Snack Food CC, Cereal CC, Starchy Vegetable II CC, NIST SRM ${ }^{\circledR} 2387$ Peanut Butter, NIST SRM ${ }^{\circledR} 3233$ Fortified Breakfast Cereal (Section 2.2) was included in each batch. Values from previous analyses of EGF and/or mEGF in the CCs [as described previously (Phillips et al., 2006)] and from the certificates of analysis for the NIST materials were used to establish expected ranges as well as to estimate analytical reproducibility of measurements across batches and laboratories.

\subsection{Data analysis}

\subsubsection{Summary statistics}

Statistical parameters [means, standard deviations (SD), percent relative standard deviations (RSD), etc.] were calculated using Microsoft ${ }^{\circledast}$ Excel $^{\circledast} 2016$ (16.0.4266.1001) (Microsoft Corporation; Redmond, WA). To evaluate analytical precision, the ratio of the assayed RSD to the expected RSD ("HorRat") was calculated according to the approach of Horwitz and Albert (2006): $\mathrm{RSD}_{\text {assayed }} /\left(\operatorname{mean}_{\text {assayed }} /\right.$ $100)^{-0.1505}$ for within laboratory data and $\mathrm{RSD}_{\text {assayed }} /(2 *($ mean assayed $/$ $100)^{-0.1505}$ ) for values from multiple laboratories, with mean values in $\mathrm{g} / 100 \mathrm{~g}$, with a HorRat of $|1.0|$ to $|2.0|$, indicating acceptable analytical precision.

\subsubsection{Means comparisons}

Analysis of variance (ANOVA) and Tukey's pairwise comparison of means (Ott and Longnecker, 2016) were performed using XLSTAT (version 19.4.45826; Addinsoft, New York, NY), with $\alpha=0.05$, in cases where multiple samples of a given food were analyzed.

Because the high cost of analysis precluded replicate analysis of samples in all cases, and consequently a single replicate was analyzed for some foods, the analytical uncertainty in single values (eSD) was estimated by using results for the control materials, as follows. For a given food sample analyzed in singlicate, the RSD for the matrix-matched control material, as percent of the mean, was calculated using all 
data for that material from the laboratories that performed the analyses for this study, and the eSD was taken to be the assayed value for the food sample times the RSD/100 for the matrix matched control material. The minimum detectable difference (MDD) was estimated for comparing singlicate analysis of EGF and mEGF in a given sample, as the sum of 2 times eSD for each value. Differences between mEGF and EGF that were less than the MDD were not considered significant. Data for samples of the following CC and RM analyzed with samples in this study (Section 2.2) were used to estimate the MDD for each food, based on similarity of matrix characteristics and/or dietary fiber content: Bread/Snack Food CC (EGF) and NIST 2387 (mEGF) for hummus, almonds, and refried beans; Bread/Snack Food CC (EGF, mEGF) for French fries, oatmeal cookies, taco shells, tortilla chips, wild rice mix); Starchy Vegetable II CC (EGF) and Fiber Vegetable CC (mEGF) for kale, cooked dried pulses, raspberry products, plantains); NIST 3233 (EGF, mEGF) for wheat bread, sunflower seeds, uncooked dried pulses; NIST 3233 (EGF) and Fiber Vegetable CC (mEGF) for popcorn. Note that the MDD as calculated is a rough estimate of analytical uncertainty, since the number of samples analyzed for the control material are not taken into account.

\section{Results}

\subsection{Quality control}

3.1.1. Control composites and standard reference materials analyzed with samples

Results for the control materials analyzed with the food samples for EGF and mEGF are summarized in Table 4. EGF was within the reference range for NIST 2387 Peanut Butter, and EGF and mEGF were within the reference range for NIST 3233 Breakfast Cereal, and the HorRat was acceptable in all of these cases $[<|3|$ (Horwitz and Albert, 2006)]. The HorRat was also acceptable for EGF in Starchy Vegetable II CC and Bread/Snack Food CC, but was high for mEGF in Cereal CC (9.3), Bread/Snack Food CC (20.5), and Fiber Vegetable CC (9.0). mEGF being the sum of values from assay of more than one fraction in a given sample is a likely reason for increased (additive) uncertainty and might also be affected by characteristics of a particular sample (discussed in Section 4.1).

\subsubsection{Minimum detectable differences}

The estimated MDD for mEGF - EGF (Section 2.6.2) ranged from $0.5 \mathrm{~g} / 100 \mathrm{~g}$ (raspberry concentrate) to $3.7 \mathrm{~g} / 100 \mathrm{~g}$ (taco shells) (Table 5A). For comparison of cooked and uncooked dried pulses, the MDD was $1.0-2.0 \mathrm{~g} / 100 \mathrm{~g}$ for EGF and $0.6-1.3 \mathrm{~g} / 100 \mathrm{~g}$ for mEGF (Table 5B). Although imperfect, this provides some basis for assessing the magnitude of differences in fiber content attributable to methodology (EGF or mEGF), relative to differences that could be attributed to analytical variability within a given methodology.

\subsection{Dietary fiber content of foods determined by EGF and $m E G F$}

\subsubsection{All foods}

The total dietary fiber content of each food measured as EGF and mEGF is summarized in Table 6 . There was no detectable difference [i.e., statistically significant and/or greater than the estimated MDD (Section 3.1.2)] between EGF and mEGF in the following products (mean EGF, mEGF g/100 g in parentheses): almonds $(10.3,10.8)$, wheat bread $(8.63,8.70)$, oatmeal cookies $(3.19,3.77)$, tortilla chips (4.87, 5.45), taco shells $(5.71,6.87)$, raw kale $(3.71,3.23)$, frozen kale (3.97, 3.99), fast food French fries $(3.79,4.57)$, or cooked pulses (except for green lentils). The largest differences between mEGF and EGF were in the uncooked dried pulses, ranging from 5.4 to $10.5 \mathrm{~g} / 100 \mathrm{~g}$ (25 to $>50 \%$ of EGF) and raw potatoes ( $13.7 \mathrm{~g} / 100 \mathrm{~g}, 585 \%$ of EGF) (see additional discussion in Ssections 3.2.2 and 3.3). Smaller differences, also with mEGF greater than EGF, were found in the following foods (difference in $\mathrm{g} / 100 \mathrm{~g}, \%$ of EGF): hummus (2.6, 44\%), canned refried beans $(0.7,18 \%)$, raspberry concentrate $(2.2,240 \%)$, raspberry pureé $(1.5,32 \%)$, boiled green and baked yellow plantains $(3.1,166 \%$ and $2.8,135 \%$, respectively), prepared wild rice mix $(1.5,164 \%)$, baked potatoes $(1.4,75 \%)$.

Interestingly, mEGF was lower than EGF in popcorn $(-1.7 \mathrm{~g} / 100 \mathrm{~g}$, $-16 \%$ of EGF), frozen raspberries $(-1.4,-30 \%)$, dry roasted sunflower seeds $(-2.2,-19 \%)$, and in prepared frozen French fries $(-1.5$, $-52 \%$ ) but not in fast food French fries (EGF $3.79 \mathrm{~g} / 100 \mathrm{~g}$, mEGF $3.99 \mathrm{~g} / 100 \mathrm{~g}$ ). Four of the five frozen French fries samples analyzed had mEGF values $<1 \mathrm{~g} / 100 \mathrm{~g}$ and one sample had $3.52 \mathrm{~g} / 100 \mathrm{~g}$. Since it was impractical to analyze replicates of each individual sample of each food, it is possible that these were analytical anomalies (see discussion in Section 4.1.3).

\subsubsection{Cooked and uncooked dried pulses and potatoes}

To compare potential changes in fiber composition measured as EGF or mEGF in cooked and uncooked dried pulses and potatoes, the fiber contents of the cooked and uncooked products were compared on a dry weight basis (Fig. 2). EGF was higher as a percent of solids in cooked versus uncooked dried pulses (5.2-24.1 g/100 g dry weight), except for red lentils, in which there was no difference. For mEGF, only lentils showed a difference, with values 6.9-7.1 g/100 g dry weight higher in cooked versus uncooked. These differences were much smaller than EGF $\mathrm{g} / 100 \mathrm{~g}$ dry weight between cooked and uncooked (15.1 for green lentils and no difference for red lentils). Based on components of fiber that would be included in mEGF and not EGF, particularly resistant starch and oligosaccharides, one would expect higher mEGF in the cooked versus uncooked pulses and little to no difference in EGF. One possible reason for the opposite trend (higher EGF on a dry weight basis and no difference in $\mathrm{mEGF}$ ) is that solids that are not part of EGF were lost during cooking (e.g., leached into the discarded cooking water), so that fiber as a percent of solids became higher in the cooked sample, but that change was countered by the inclusion of resistant starch and oligosaccharides in fiber measured by mEGF but not EGF.

In contrast, in the potatoes, there was no difference in EGF $\mathrm{g} / 100 \mathrm{~g}$ dry weight in raw and baked potatoes, but mEGF $71.4 \mathrm{~g} / 100 \mathrm{~g}$ dry weight was higher in the raw potatoes. Type 1 resistant starch (Section 4.1.2.1) in potatoes (Raatz et al., 2016) could explain these results, given that the EGF analysis likely made the potato starch accessible to the digestive enzymes during the autoclaving step that is part of the analysis, and there was no potential for loss of solids as in the cooking of the dried pulses.

\section{Discussion}

\subsection{Possible reasons for difference, or lack of difference, in fiber analyzed} by EGF and $m E G F$

There are four basic elements that affect the results for fiber determined by EGF versus mEGF: a) methodological parameters that affect extraction or inclusion of dietary fiber components; b) composition of fiber in a given food; c) analytical uncertainty, due to the tedious nature of the assays; d) sample processing during analysis that (unintentionally) affects fiber content/composition relative to the food as consumed.

\subsubsection{Methodological differences}

As highlighted in Fig. 1, the main differences between the EGF and mEGF methods are, in mEGF, elimination of the autoclaving prior to amylase treatment, lower temperature and longer time for enzyme incubations, and measurement and inclusion of non-digestible oligosaccharides, by high-performance liquid chromatography of the soluble portion of the fiber digest. Others have discussed the potential disparity in the fiber content of foods determined by these two approaches and/ or actually measured the contents in different foods (Aldwairji et al., 
Table 4

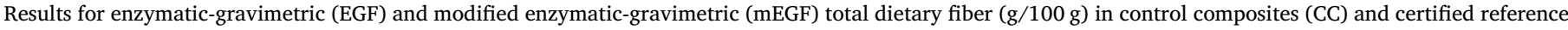

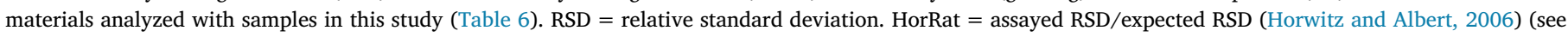
Section 2.5).

\begin{tabular}{|c|c|c|c|c|c|c|c|c|c|c|}
\hline \multirow[b]{2}{*}{ Material } & \multirow[b]{2}{*}{ Method $^{\mathrm{a}}$} & \multirow[b]{2}{*}{ Lab Code } & \multirow[b]{2}{*}{$n$} & \multirow[b]{2}{*}{ Mean } & \multirow[b]{2}{*}{ SD } & \multirow[b]{2}{*}{$\%$ RSD } & \multirow[b]{2}{*}{ HorRat } & \multicolumn{2}{|c|}{ Expected range for material } & \multirow[b]{2}{*}{ Source of expected range ${ }^{b}$} \\
\hline & & & & & & & & Low & High & \\
\hline \multirow[t]{2}{*}{ Cereal CC ${ }^{\mathrm{c}}$} & EGF & \multicolumn{9}{|c|}{ not analyzed } \\
\hline & mEGF & A & 2 & 10.1 & 1.32 & 13.1 & 9.3 & No data & & \\
\hline \multirow[t]{2}{*}{ Bread/Snack Food CC } & EGF & $\mathrm{A}, \mathrm{B}$ & 9 & 3.31 & 0.26 & 7.9 & 2.4 & 2.44 & 3.73 & NFNAP \\
\hline & mEGF & A & 4 & 4.46 & 1.46 & 32.7 & 20.5 & No data & & \\
\hline \multirow[t]{2}{*}{ Fiber Vegetable CC $^{\mathrm{e}}$} & EGF & A & 1 & 2.5 & & & & & & \\
\hline & mEGF & A, B & 2 & 2.70 & 0.84 & 31.1 & 9.0 & 1.52 & 4.45 & NFNAP \\
\hline \multirow[t]{2}{*}{ NIST SRM ${ }^{\oplus} 2387$ Peanut Butter } & EGF & B & 1 & 5.26 & & & & 5.15 & 5.99 & $\mathrm{COA}$ \\
\hline & mEGF & B & 2 & 6.65 & 0.07 & 1.1 & 0.7 & No data & & \\
\hline \multirow[t]{2}{*}{ NIST SRM ${ }^{\oplus} 3233$ Fortified Breakfast Cereal } & EGF & A, B & 2 & 8.60 & 0.23 & 2.7 & 0.9 & 7.8 & 10.2 & $\mathrm{COA}$ \\
\hline & mEGF & A & 5 & 11.8 & 0.24 & 2.0 & 1.5 & 11.46 & 13.02 & $\mathrm{COA}$ \\
\hline \multirow[t]{2}{*}{ Starchy Vegetable II CC ${ }^{f}$} & EGF & A, B & 5 & 2.89 & 0.52 & 17.9 & 5.3 & 2.2 & 3.0 & NFNAP \\
\hline & mEGF & not analyzec & & & & & & & & \\
\hline
\end{tabular}

a $\mathrm{EGF}=$ enzymatic-gravimetric total dietary fiber (AOAC 991.43) (AOAC, 2005a); mEGF = modified enzymatic-gravimetric total dietary fiber (AOAC 2009.01, 2011.25) (AOAC, 2011, 2012).

b NFNAP = Tolerance limits calculated from USDA National Food and Nutrient Analysis Program (NFNAP) (Haytowitz and Pehrsson, 2018), as described previously (Phillips et al., 2006); COA = reference range from certificate of analysis [National Institute of Standards and Technology (NIST), 2014, 2015].

c Multigrain toasted oat breakfast cereal.

d Mixture of refrigerated biscuits (baked), whole wheat bread, white corn tortilla chips, corn muffins (prepared from mix), pound cake, oat bran muffins, and scones.

e Mixture of canned (drained) chickpeas, raw orange sweet potatoes (peeled), ripe bananas (peeled), baked russet potatoes (with skin), raw russet potatoes (without skin), raw kale (leaves only), and raw white onions (peeled).

${ }^{\mathrm{f}}$ Mixture of canned (drained) spinach, potatoes (without skin), refried beans, and vegetarian vegetable soup; baby food sweet potatoes and corn; non-iodized salt.

2014; Chen et al., 2016; Food Standards Australia New Zealand, 2017);

Hollmann et al., 2013; Maningat et al., 2013; Pastell and Putkonen,

2014; Tobaruela et al., 2018).

\subsubsection{Composition of dietary fiber}

These modifications would theoretically lead to a difference in EGF and mEGF in some foods in this study (Table 3 ) as a consequence of the different components of dietary fiber affected (Fig. 3). From a practical

Table 5

Minimum detectable difference (MDD) (Section 2.6.2) between total dietary fiber measured by enzymatic-gravimetric analysis (EGF) (AOAC, 2005) and modified enzymatic-gravimetric method (mEGF) AOAC, 2011, 2012) (A), and for difference in eGF and mEGF in cooked versus uncooked dried pulses (B).

\begin{tabular}{|c|c|c|c|}
\hline \multicolumn{4}{|l|}{ A } \\
\hline Food & mEGF - EGF (g/100 g) & Food & mEGF - EGF $(g / 100 g)$ \\
\hline Raspberries, concentrate & 0.5 & Lentils, red, uncooked & 1.7 \\
\hline Potatoes, with skin, baked & 0.6 & Popcorn, microwave, butter flavor & 1.8 \\
\hline Refried beans, canned & 0.7 & Peas, yellow, uncooked & 1.8 \\
\hline Wheat bread, 45 calorie & 0.8 & Almonds, dry roasted, salted & 1.9 \\
\hline Kale, fresh, raw & 0.8 & Peas, green, uncooked & 2.0 \\
\hline Plantains, green, boiled & 0.9 & Oatmeal cookies with raisins & 2.1 \\
\hline Plantains, yellow, baked & 0.9 & Chickpeas, cooked & 2.2 \\
\hline Sunflower seeds, dry roasted & 0.9 & Lentils, green, cooked & 2.2 \\
\hline Raspberries, frozen & 0.9 & Lentils, green, uncooked & 2.2 \\
\hline Hummus & 1.0 & Potatoes, with skin, raw & 2.4 \\
\hline Kale, frozen & 1.0 & French fries, fast food & 2.5 \\
\hline Wild rice mix, prepared & 1.1 & Peas, yellow, cooked & 2.7 \\
\hline Lentils, red, cooked & 1.3 & Peas, green, cooked & 2.7 \\
\hline French fries, frozen, prepared & 1.3 & Tortilla chips, white corn & 3.0 \\
\hline Raspberries, puree & 1.3 & Taco shells, yellow corn & 3.7 \\
\hline Chickpeas, uncooked & 1.5 & & \\
\hline
\end{tabular}

B

\begin{tabular}{|c|c|c|c|c|}
\hline \multirow[b]{2}{*}{ Sample $^{\mathrm{b}}$} & \multicolumn{2}{|c|}{$\mathrm{g} / 100 \mathrm{~g}$ dry weight } & \multicolumn{2}{|c|}{$\mathrm{g} / 100 \mathrm{~g}$ fresh weight ${ }^{\mathrm{a}}$} \\
\hline & EGF & mEGF & EGF & mEGF \\
\hline Peas, yellow & 5.7 & 3.2 & 1.6 & 0.9 \\
\hline Peas, green & 6.0 & 3.9 & 2.0 & 1.3 \\
\hline Lentils, green & 2.7 & 2.7 & 1.0 & 0.9 \\
\hline Lentils, red & 3.2 & 1.9 & 1.0 & 0.6 \\
\hline Chickpeas & 3.4 & 2.4 & 1.2 & 0.8 \\
\hline
\end{tabular}

a Equivalent fresh weight basis, calculated based on analyzed moisture content of cooked sample.

b For sample analyzed both cooked and raw, for each pulse (Table 3). 
Table 6

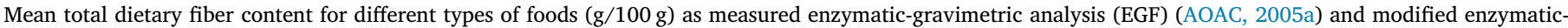

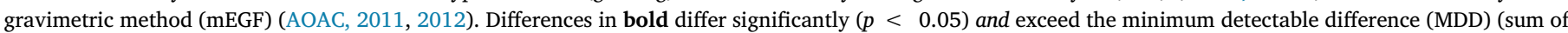

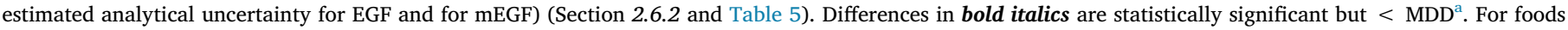
with $n=1$ differences $>$ MDD are noted as significant.

\begin{tabular}{|c|c|c|c|c|c|c|c|c|}
\hline \multirow{3}{*}{ Food } & \multicolumn{7}{|c|}{ Total Dietary Fiber } & \multirow[b]{3}{*}{ mEGF-EGF $(\mathrm{g} / 100 \mathrm{~g})^{\mathrm{e}}$} \\
\hline & & EGF & & & mEGF & & & \\
\hline & $n^{\mathrm{b}}$ & Mean & Low & High & Mean & Low & High & \\
\hline \multicolumn{9}{|l|}{ Dried pulses: } \\
\hline Peas, yellow Cooked & 4 & 11.6 & 9.16 & 13.7 & 10.5 & 8.96 & 13.2 & -1.2 \\
\hline Uncooked & 1 & 17.8 & & & 28.3 & & & 10.5 \\
\hline Peas, green Cooked & 3 & 11.8 & 8.02 & 15.1 & 11.2 & 9.78 & 12.5 & -0.6 \\
\hline Uncooked & 1 & 22.2 & & & 28.1 & & & 5.9 \\
\hline Lentils, green Cooked & 3 & 7.3 & 4.2 & 10.9 & 10.1 & 9.21 & 11.3 & 2.8 \\
\hline Uncooked & 1 & 24.3 & & & 29.8 & & & 5.5 \\
\hline Lentils, red Cooked & 2 & 5.5 & 5.0 & 6.0 & 5.5 & 5.35 & 5.66 & 0.0 \\
\hline Uncooked & 1 & 18.1 & & & 23.9 & & & 5.8 \\
\hline Chickpeas Cooked & 3 & 8.1 & 6.57 & 9.84 & 9.5 & 8.89 & 10.8 & 1.4 \\
\hline Uncooked & 1 & 16.4 & & & 21.8 & & & 5.4 \\
\hline \multicolumn{9}{|c|}{ Processed Nuts, Seeds, and Legume Products: } \\
\hline Sunflower seeds, dry roasted, salted & 5 & 11.5 & 7.26 & 18.8 & 9.32 & 7.30 & 12.3 & -2.2 \\
\hline Almonds, dry roasted, salted & 8 & 10.3 & 9.4 & 11.5 & 10.8 & 10.4 & 11.3 & 0.5 \\
\hline Hummus & 6 & 5.01 & 4.30 & 5.73 & 7.6 & 7.1 & 8.0 & 2.6 \\
\hline Refried beans, canned, traditional & 6 & 3.84 & 3.59 & 4.02 & 4.53 & 4.00 & 5.20 & 0.70 \\
\hline \multicolumn{9}{|l|}{ Processed Grain Products: } \\
\hline Wild rice mix, prepared & 1 & 0.90 & & & 2.38 & & & 1.5 \\
\hline Wheat bread, 45 calorie & 4 & 8.63 & 7.98 & 9.63 & 8.70 & 8.20 & 9.49 & 0.1 \\
\hline Oatmeal cookies with raisins & 5 & 3.19 & 2.64 & 3.81 & 3.77 & 3.59 & 4.06 & 0.58 \\
\hline Tortilla chips, white corn & 6 & 4.87 & 4.24 & 5.85 & 5.45 & 4.86 & 6.22 & 0.6 \\
\hline Taco shells, yellow corn & 12 & 5.71 & 4.23 & 7.03 & 6.87 & 4.70 & 8.32 & 1.2 \\
\hline Popcorn, microwave, butter, prepared & 6 & 10.8 & 9.04 & 13.05 & 9.11 & 7.87 & 10.9 & -1.7 \\
\hline \multicolumn{9}{|l|}{ Other Foods: } \\
\hline Plaintains green, boiled & 1 & 1.86 & & & 4.94 & & & 3.1 \\
\hline yellow, baked & 1 & 2.09 & & & 4.92 & & & 2.8 \\
\hline Potatoes, with skin raw & 2 & 2.11 & 2.05 & 2.17 & 15.8 & 15.3 & 16.2 & 13.6 \\
\hline baked & 2 & 1.82 & 1.70 & 1.93 & 3.20 & 3.08 & 3.31 & 1.4 \\
\hline Raspberries frozen & 1 & 4.69 & & & 3.26 & & & -1.4 \\
\hline pureé & 1 & 4.72 & & & 6.21 & & & 1.5 \\
\hline concentrate & 1 & 0.916 & & & 3.16 & & & 2.2 \\
\hline Kale fresh, uncooked & 5 & 3.71 & 3.16 & 4.19 & 3.23 & 2.69 & 3.63 & -0.5 \\
\hline frozen, uncooked & 6 & 3.97 & 3.62 & 4.33 & 3.99 & 3.44 & 4.57 & 0.0 \\
\hline French fries fast food & 6 & 3.79 & 3.46 & 4.02 & 4.57 & 3.63 & 5.76 & 0.8 \\
\hline frozen, prepared & 5 & 2.80 & 2.37 & 3.17 & 1.34 & 0.75 & 3.52 & -1.46 \\
\hline
\end{tabular}

a MDD for each food (g/100 g): yellow peas uncooked (2.3), cooked (7.7); green peas uncooked (2.5), cooked (8.2); green lentils uncooked (2.7), cooked (7.0); red

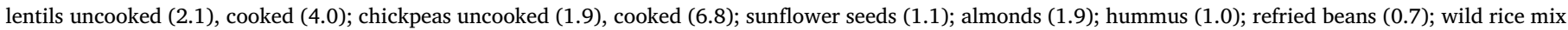

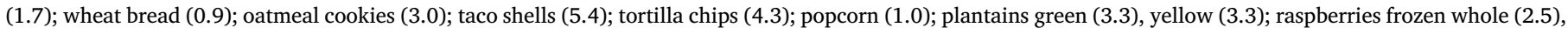
pureé (4.3), concentrate (2.1); kale fresh (2.4), frozen (2.9); French fries fast food (3.6), frozen/prepared (1.3).

b Number of samples analyzed for EGF and for mEGF.

c EGF = enzymatic-gravimetric total dietary fiber (AOAC 991.43) (AOAC, 2005a); mEGF = modified enzymatic-gravimetric total dietary fiber (AOAC 2009.01, 2011.25) (AOAC, 2011, 2012).

d Differences in significant digits reflect the precision of values as reported.

e Difference between mean mEGF and mean EGF.

standpoint, differences in assayed values would depend not only on the concentration and content of particular dietary fiber components in a given food, but also the concentrations must be high enough to overcome the variability and limits of detection that are characteristic of the enzymatic-gravimetric approach (Section. 4.1.3).

4.1.2.1. Resistant starch. Resistant starch (RS) is starch that is not hydrolyzed by digestive enzymes and passes to the large intestine, fitting the definition of "dietary fiber". There is extensive literature on RS, and its relationship to dietary fiber (Berry, 1986; Dai and Chau, 2017; Food Standards Australia New Zealand, 2017; Perera et al., 2010; Raigond et al., 2015) Enzymatic gravimetric methods for measuring fiber include RS to varying degrees depending on the type of RS, of which there are five classifications: Type 1 is physically inaccessible to amylase and amyloglucosidase, that can become hydrolyzable after cooking (gelatinization); Type $2 \mathrm{RS}$ is inaccessible to enzymes, due to the conformation of the starch granule; Type 3 is retrograded (crystalline, non-granular) starch, formed in processed foods after cooking and cooling or drying; Type 4 comprises starches that have been chemically modified to render them resistant to enzymatic degradation; Type 5 is an amylose-lipid complex found in some foods, that is resistant to digestion (Fuentes-Zaragoza et al., 2011). Type 1 RS is not measured as dietary fiber by EGF methodology because the initial autoclaving step gelatinizes the starch. For uncooked foods, fiber content of the food would be underestimated. On the other hand, Type 1 RS would be included in dietary fiber by the mEGF approach, in 
which the autoclaving step is omitted (Fig. 1), and dietary fiber measured by mEGF would be expected to be higher in uncooked foods containing Type 1 RS. Potatoes and dried pulses in this study showed a dramatic difference in mEGF (but not EGF) in raw versus cooked samples, and in total fiber measured by mEGF versus EGF in the raw products (Section 3.2.2). These foods are not typically consumed uncooked, but the degree of gelatinization of the RS, and hence total fiber measured by mEGF versus EGF, could vary based on cooking time and method. In this study only cooked plantains were analyzed, and fiber measured by mEGF relative to EGF was only moderately higher $(\sim 3 \mathrm{mg} / 100 \mathrm{~g}$ ) suggesting that some of the starch may not have been fully cooked in the prepared plantains, and/or the presence of another form of RS. Soares at al. (2011) have reported on the resistance of starch to hydrolysis due to conformation of starch granules in plantains.

Type $3 \mathrm{RS}$ is likely in baked products, cooked and cooled pastas (e.g., frozen dinners), or dried, extruded or otherwise processed highstarch foods. EGF and mEGF methods (and different methods for direct determination of RS) have been reported to variably include retrograded starch (Food Standards Australia New Zealand, 2017). In the present study, several foods likely to contain Type 3 RS were analyzed (wheat bread, oatmeal cookies, taco shells, tortilla chips, popcorn). No statistically significant difference were found in total fiber measured by mEGF and EGF. However, the wide range in values among samples (1.2-4.0 and 0.5-3.6 g/100 g for EGF and mEGF, respectively) suggests variability among samples or of analytical variability that limit ability to detect differences, despite documented and variable effects of processing on resistant starch content measured directly (e.g., Berry, 1986; Raatz et al., 2016).

4.1.2.2. Non-digestible oligosaccharides and products of polysaccharide hydrolysis. The current definition of dietary fiber allows for inclusion of non-digestible oligosaccharides (see Table 1), such as raffinose, stachyose, and verbascose, endogenous to legumes (Brummer et al., 2015; Fan et al., 2015) and other foods, as well as hydrolysis products of non-starch polysaccharides [e.g., fructo-oligosaccharides from inulin (Roberfroid, 2005)] and some types of starch (created during processing, for example) (Grootaert et al., 2007; Mussatto and Mancilha, 2007; Swennen et al., 2006), designated as "low molecular weight soluble dietary fiber" (LMWSDF) in the mEGF assay. If LMWSDF is present in a given food, there should theoretically be a higher fiber content measured by mEGF versus EGF, measured as LMWSDF by the mEGF assay. Since the oligosaccharides can be leached into cooking water (e.g., boiled vegetables and legumes), variation in cooking method could affect the degree to which these components are removed during cooking. For example, how dried beans are prepared varies widely in terms of soaking or not prior to cooking, whether or not soaking liquid was discarded, the ratio of water to dried beans, cooking time and temperature and method (e.g., boiling, pressure cooking, commercial canning). In the present study, the only statistically significant difference found between $\mathrm{mEGF}$ and EGF in cooked dried pulses was for green lentils (mEGF $2.8 \mathrm{~g} / 100 \mathrm{~g}$ higher than EGF). The water to weight of dry pulse cooked was lower for lentils compared to the other pulses, and lower for green lentils than red lentils (Table 3). It is not unreasonable to assume that more of the cooking water was absorbed into the lentils, and thus more LMSWDF would be retained in the cooked pulse as consumed. These differences in cooking in this study represent normal variations in actual cooking parameters that might occur. The volume of water used for cooking each type of pulse was based on the ratio to the volume of soaked pulse (dry volume for lentils, which were not soaked), and differences in the expansion from soaking led to differences in water volume to dry weight ratios (Table 3). Retention of cooking water might also be greater in canned and pressure-cooked beans. More research is warranted on the effects of different cooking and processing methods on LMWSDF in foods as consumed, for products having a high LMWSDF in the uncooked food. It is also worth noting that sample preparation in literature reports on measurement of dietary fiber, or in samples analyzed to generate food composition data, can vary significantly in ways that might affect retention of LMWSDF. For example, Chen et al. (2016) determined dietary fiber by a modified enzymatic-gravimetric assay in which oligosaccharides (raffinose, stachyose, verbascose) were measured on a separate portion of the bean sample (Kleintop et al., 2013) in several types of cooked dried beans, but the cooking was done on the beans after they were ground to a powder, autoclaved in water, cooled to room temperature, and homogenized with the cooking water. Comparing results on a $\mathrm{g} / 100 \mathrm{~g}$ dry weight basis (because that is the only way data were reported by Chen et al., 2016), mEGF in our study was 26-30, 33.1, and 26.3-27.8 for chickpeas, Aragorn peas, and lentils, respectively, compared to 19.9-24.9, 23.4-25.6, and 19.8-20 in the Chen et al. report, where oligosaccharide contents ranging from 2 to $4.4 \mathrm{~g} / 100 \mathrm{~g}$ dry weight were found across these products. We would expect the values to be lower in our study, but comparison is likely confounded by comparing data on a dry weight basis, since the total solids (i.e. the denominator when food component is calculated on a dry weight basis) may change as a result of leaching of fiber (and other components) to cooking water, as discussed in Section 3.2.2, highlighting another challenge in comparing data from different studies for the "same" food.

On the other hand, McCleary (2014) has reported on maltodextrins resulting from amylolysis, that are resistant to the bacterial enzymes used in the enzymatic-gravimetric dietary fiber methods, but are digested in vivo and therefore should not be counted as dietary fiber, and

“Enzymatic-Gravimetric" Method (AOAC 985.29)

Modified Enzymatic-Gravimetric (“McCleary”) Method (AOAC 2009.01, 2011.25)

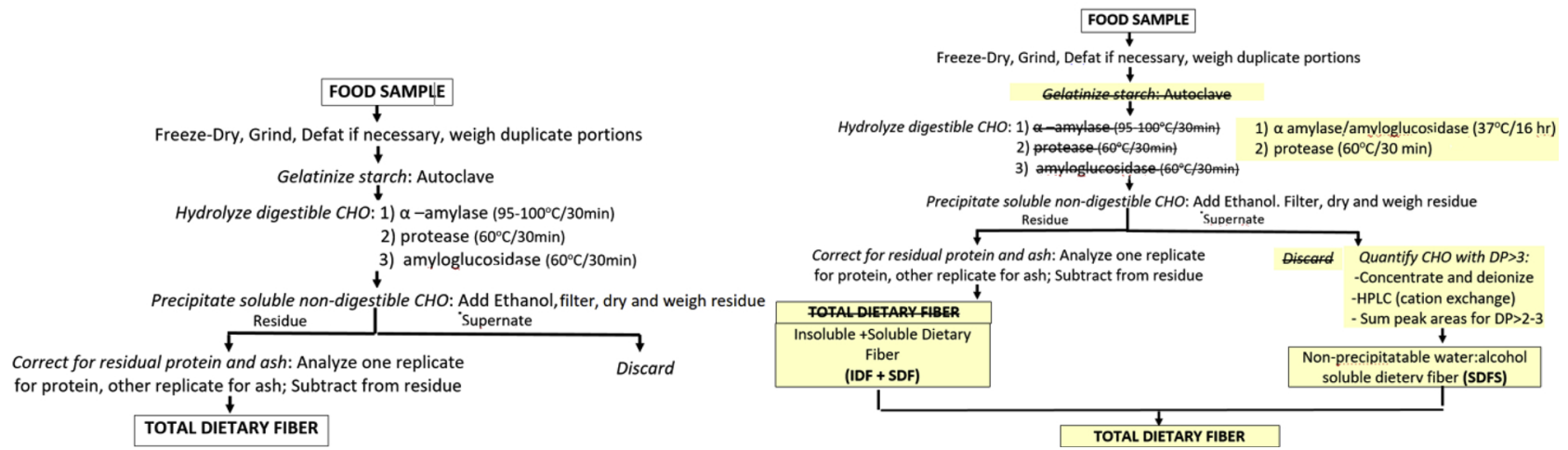

Fig. 1. Methodological differences in historic enzymatic-gravimetric analysis of total dietary fiber (method 985.29; AOAC, 2005b) and the modified enzymaticgravimetric method introduced in 2009 (methods 2009.01 and 2011.25; AOAC, 2011, 2012). Steps that differ are highlighted in the modified method. 
A

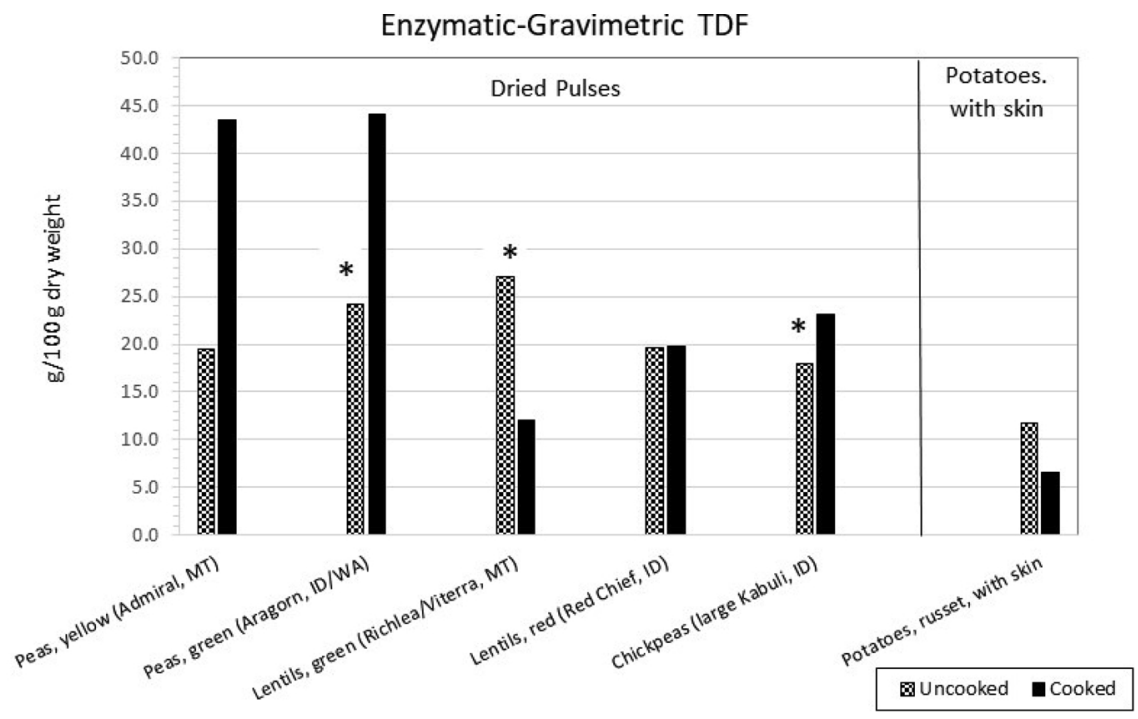

B

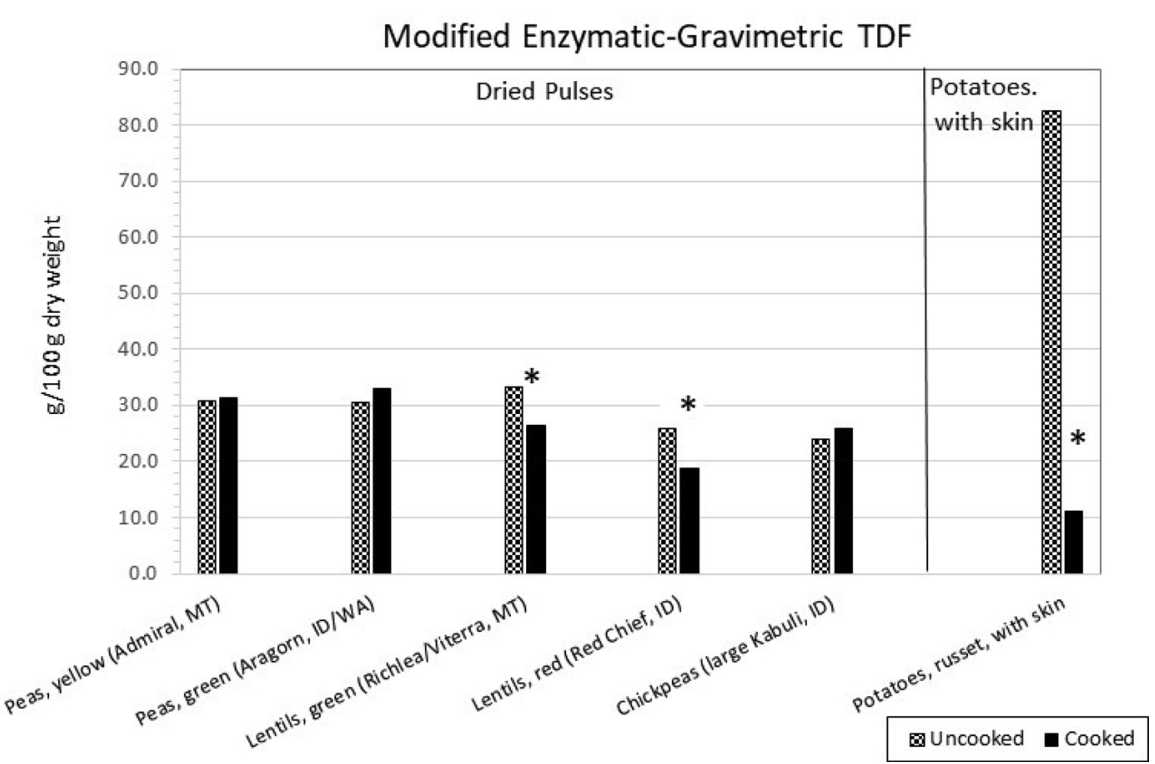

Fig. 2. Total dietary fiber in dried pulses uncooked and cooked (Table 3) and potatoes raw and baked (Section 2.1), on a dry weight basis, as analyzed by (A) enzymatic-gravimetric (EGF) (AOAC, 2005a, b) and (B) modified enzymatic-gravimetric (mEGF) (AOAC 2009.01, 2011.25; AOAC, 2011, 2012) methods. * Indicates values that differ statistically. Pulses were cooked by boiling and potatoes were baked (see Section 2.1).

\section{A. Enzymatic-Gravimetric Method}

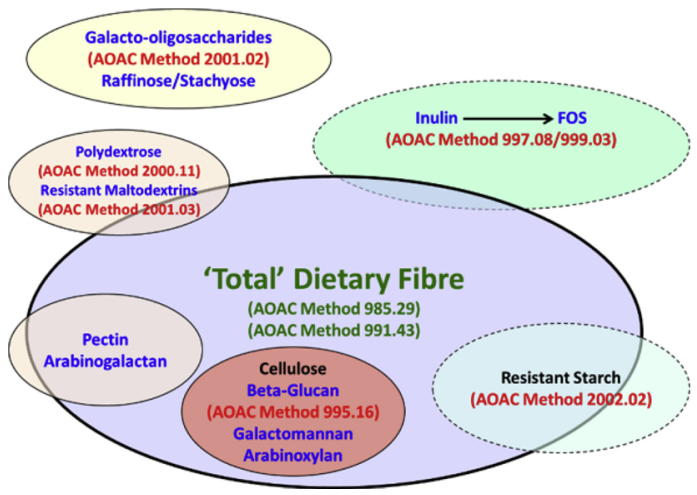

B. Modified Enzymatic-Gravimetric Method. (All components enclosed in rectangular area are measured as dietary fiber)

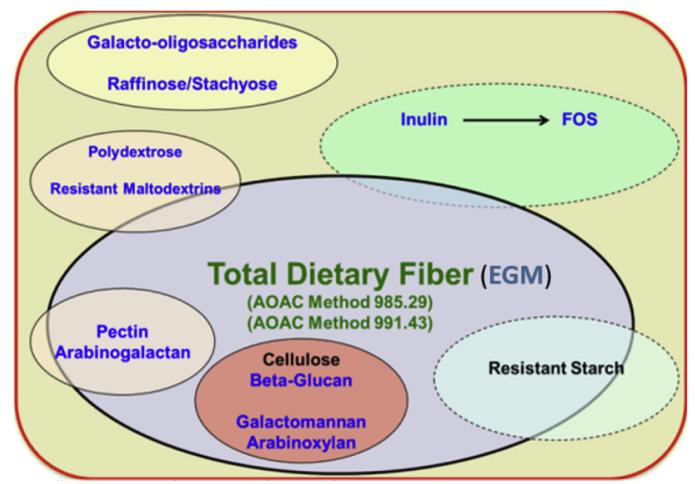

Fig. 3. Components included in "dietary fiber" measured by historic enzymatic-gravimetric analysis of total dietary fiber (AOAC, 2005a, b) and the modified enzymatic-gravimetric (mEGF) (AOAC, 2011, 2012). FOS = fructo-oligosaccharides. Reprinted from McCleary et al. (2013), with permission. 
proposed a modification of methodology. The amount of these maltodextrins depends on the starch structure and amount of starch in a particular food (McCleary, 2014). Whether or not a laboratory uses the modified method for determining LMWSDF is also variable.

\subsubsection{Measurement uncertainty}

The relatively high RSDs for the control materials assayed across multiple batches (Table 4) are not surprising, given that the gravimetric assay actually involves multiple analyses (gravimetric determination of fiber residue, and measurement of residual protein and ash, plus, in mEGF, the HPLC analysis of LMWSDF), and also involves many steps of the assay and the small differences in weight being measured.

The digests after enzyme treatments are filtered through a tared glass crucible with filtering aid (Celite ${ }^{\circledast}$, diatomaceous earth), and the entire crucible plus filtering aid plus residue is dried and weighed. This limitation is likely the reason the standard methods specify concentrated (freeze dried) food samples. However, as described in Section 4.1.4, this treatment can actually alter dietary fiber components. If the sample is assayed without drying and without a corresponding increase in the sample weight and amount of buffer, very low differences in weight are being measured. For example, a sample containing $3 \mathrm{~g} \mathrm{EGF/}$ $100 \mathrm{~g}$ has $0.03 \mathrm{~g}$ EGF in a one gram sample taken for analysis. The total weight of crucible plus filtering aid is approximately $40 \mathrm{~g}$, which means that a $0.075 \%$ difference in weight must be precisely measured, with the tare and final weights being taken a day apart in some cases.

The crucible and filtering aid are dried before weighing, and again with the fiber residue before obtaining the final weight, but the diatomaceous earth is hygroscopic. Moisture can be picked up during the process of weighing at either point, depending on the relative humidity and how well it is controlled. Small amounts of Celite ${ }^{\circledR}$ could also be lost during handling of the crucibles during the assay. Additionally, the assay involves carrying through two replicates of a sample, one of which is destructively analyzed for residual protein and ash, and those contents are subtracted from the weight of the other replicate. Not only is there the assumption that the two samples carried through the assay have the exact same concentrations of these analytes, these assays have their own measurement uncertainty, which is significant given the low concentrations being measured. The Kjeldahl protein assay is crude and was designed for measurement of nitrogen in foods, with a correction factor for conversion to protein that differs for some foods and is based on the assumption that most food proteins contain 16\% nitrogen (Jones, 1931). The source of residual protein in the fiber residue in enzymaticgravimetric dietary fiber assays is primarily the protease enzyme and possibly insoluble peptides if the food protein was incompletely digested. The conversion factor of 6.25 specified to convert Kjeldahl nitrogen to protein in the standard EGF methods is what is used for most intact foods, but may not be accurate for the concentration by weight, even among foods of the same type (Fujihara et al., 2001), let alone for the residual protein in the fiber residue.

In the mEGF assay, the supernatant from which the soluble fiber is precipitated is also subjected to an HPLC analysis to measure the LMWSDF. Again, since the assay was not optimized based on the content of these components in the original sample, very low concentrations of total LMWSDF, and even lower levels of the multiple individual analytes quantified as part of that analysis, can lead to values below the limit of quantitation, even if the original sample contains a meaningful amount. Some researchers have modified the method to assay oligosaccharides separately from the fiber analysis, in a separate subsample of the material being tested, using optimized sample size and other method parameters for those analytes (e.g., Chen et al., 2016). While this approach is definitely preferable to obtain a better measure of oligosaccharides, and to obtain separate values for particular chemical compounds comprising "dietary fiber", it could exclude other components of LMWSDF. All of these factors contribute to measurement uncertainty in the gravimetric determination. And, in the case where soluble and insoluble fiber are measured separately and added together to get total fiber (as in AOAC 991.43 for EGF, or the mEGF assay, which also includes separate assay of oligosaccharides in the supernatant after enzymatic digestion).

All of these factors become even more significant based on the analytical sample size and its fiber content. Particularly if, as in some laboratories, the sample is analyzed without freeze-drying and no adjustment to sample size (based on dried weight in the standard methods as written) is made to allow for the moisture content, even smaller residue weights will be measured, leading to values below LOQ. In this study (data not reported), when a $0.5 \mathrm{~g}$ sample size (not freeze-dried) was used for EGF in the Starchy Vegetable II CC ( $22 \%$ moisture), dietary fiber was less than the limit of quantitation $(0.75 \mathrm{~g} / 100 \mathrm{~g}$ ) (data not shown), when the established concentration is $2.2-3.0 \mathrm{~g} / 100 \mathrm{~g}$ (Table 4). Samples of similar matrix (potatoes) assayed in the same batch with same sample size also had < LOQ values. This example also highlights the critical role of control materials in ongoing analysis of dietary fiber (and other food components).

\subsubsection{Sample processing that is part of the assay}

Both assays prescribe extraction of fat from high fat samples, freezedrying and grinding of samples to a standardized particle size. However, these steps are not always performed by all laboratories or consistently for all food samples, yet may affect the digestion and amount or recovery of fiber from some foods. Research has shown that processing affects solubility and structure of pectin (Menoli and Beleia, 2007; Plat et al., 1988; Qi et al., 2000; Ralet et al., 1991; Thakur et al., 1997; Van Buren, 1986), and freeze-drying can change the fiber content and composition in some foods (Phillips and Palmer, 1991). Freezing alone (which was the standard protocol for homogenized samples in the present study, as in most laboratories) could affect sugar composition (Li et al., 1985) and development of resistant starch in some foods (Perera et al., 2010; Raigond et al., 2015), and disrupts cell walls in raw vegetables and fruits, which affects accessibility of enzymes to starch and the extractability of other components. The particle size to which grains are ground has been shown to affect starch digestion (Berry, 1986; Fuentes-Zaragoza et al., 2011). Similarly, when seeds are present as part of a food (e.g., poppy seed muffins) they likely would not be broken up when that food is homogenized for analysis. Yet when seeds are analyzed in isolation, they typically would be ground. The effect of seeds on gravimetrically determined dietary fiber has been demonstrated (Cranker et al., 1997). Thus, the manner in which a sample is prepared for analysis can thus affect dietary fiber content, and to a different extent for EGF and mEGF, further confounding comparison of results between laboratories and methods, and relative to the content in the food as consumed.

\subsection{Implications for food composition databases and nutrition research}

The impact of the changing and variable definition of dietary fiber over time and among different organizations and databases presents challenges for epidemiological and food composition research and the changing needs for more specific data for the health-diet interface. Others have also commented on these issues (Jones, 2014; Stephen et al., 2017; Westenbrink et al., 2013; Zielinski et al., 2013). As the definition of and methodology for measuring "dietary fiber" have changed over time, so have the values. Values for the same food in different databases also may not represent the content of the very same food components, due to definitional and/or methodological disparities. Consequently, epidemiological studies using food composition data to estimate fiber intake draw conclusions based on whatever is the current definition (and quality and completeness of data) in the food composition database used at the time. And, if dietary fiber values in food composition databases used in such studies, such as the USDA databases (U.S. Department of Agriculture, 2016, 2019) and other national food composition databases are replaced with values based on changing definition and methods, it will be impossible to relate findings 
A.

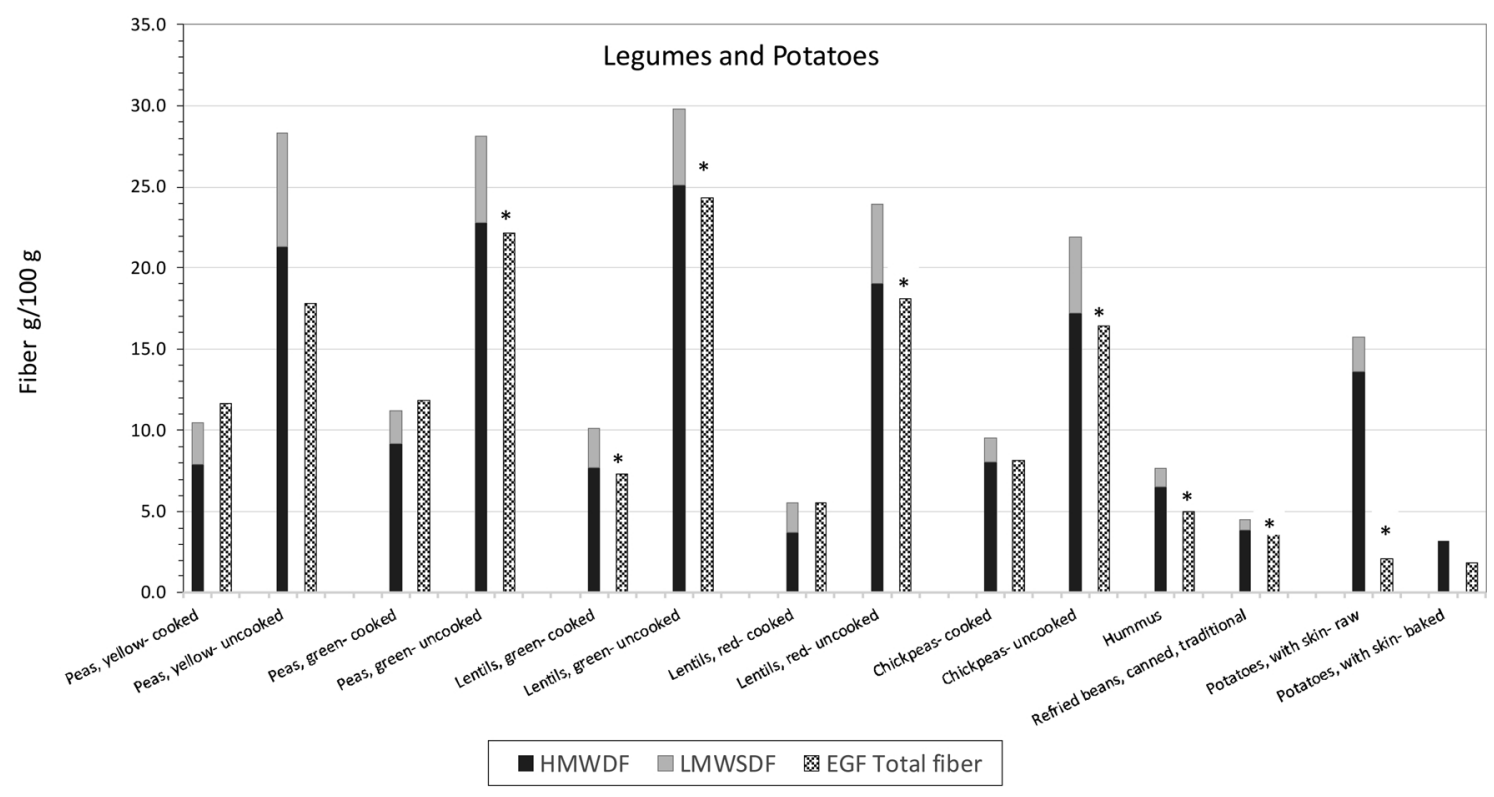

B.

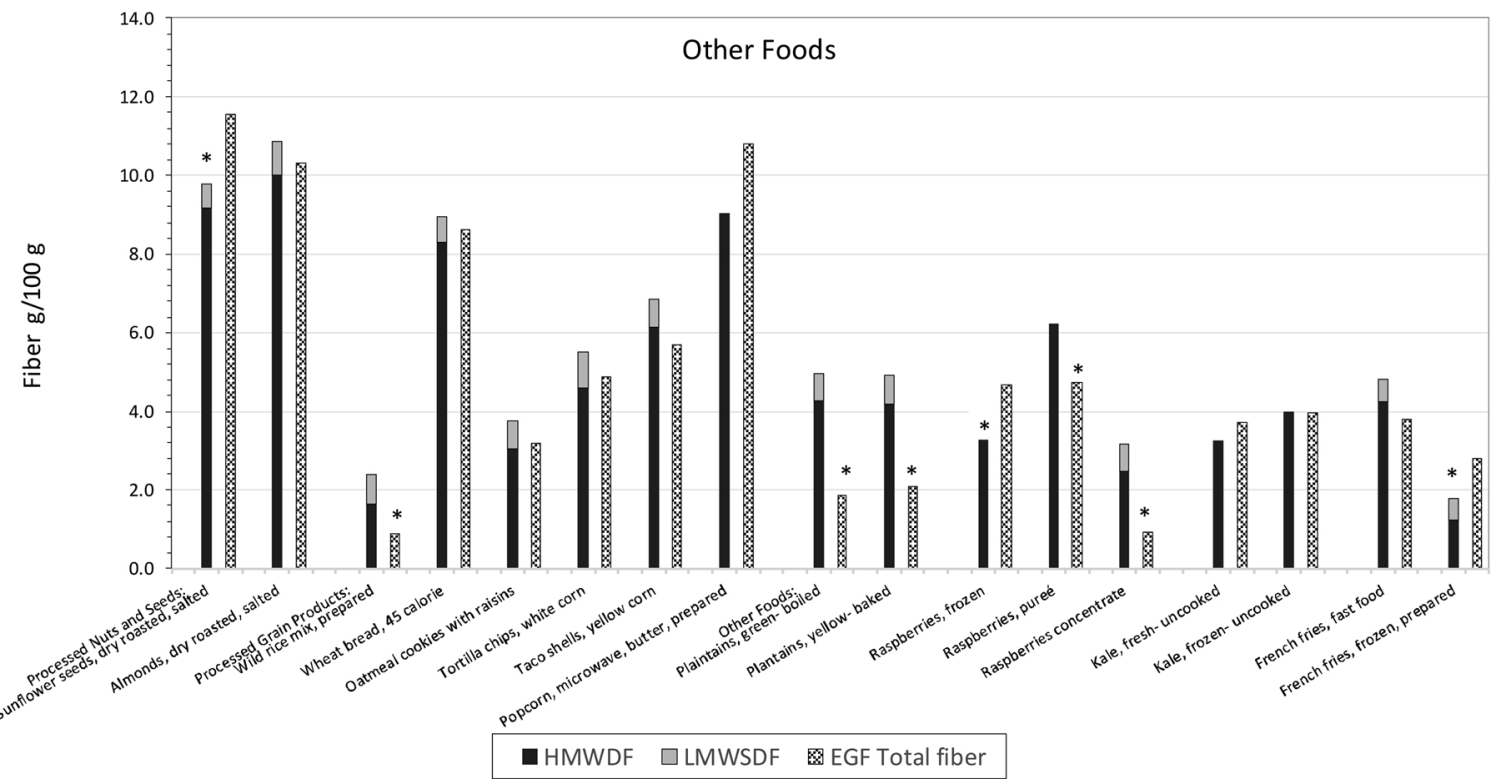

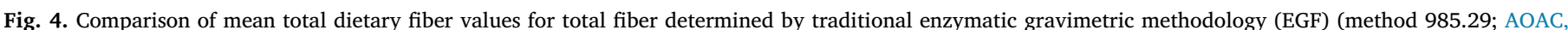

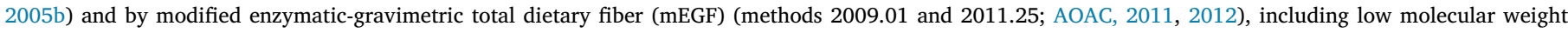

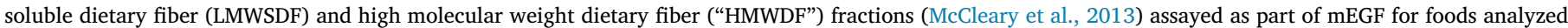
(Table 6).

on the effects of "dietary fiber" intake to health outcomes in observational and cohort studies conducted, at different points in time, or over time in prospective studies, or in meta-analyses (e.g., Bazzano et al., 2003; Buil-Cosiales et al., 2016; Chiavaroli et al., 2015; Dai et al., 2017; Veronese et al., 2018; Yang et al., 2015; Wu et al., 2015; among many others). Because processed food formulations change, it is not possible to simply recalculate past intake using data for the current food supply (Fig. 4).

It is important to note that whether or not differences between mEGF and EGF fiber were statistically significant in this study; the values determined by either method are what would be reported as the food values in the database, in each case. When (as in typical use) a food mean value is used, there could be an apparent difference in EGF and mEGF values when there is no statistically significant difference (i.e. due to food or analytical variation), or, conversely a difference when there really is not, due to methodological factors. An advantage of the present study, from a food composition database perspective, is that comparison of dietary fiber values determined by EGF versus $\mathrm{mEGF}$ for a given food were obtained for multiple samples and preparations of the same food, rather than repeated measurements on the same sample by the two methods. This approach better represents the way mean values for a food composition database would be generated, by including sample differences (unlike studies that are designed to compare methodology). Sometimes ingredient or processing differences in apparently 


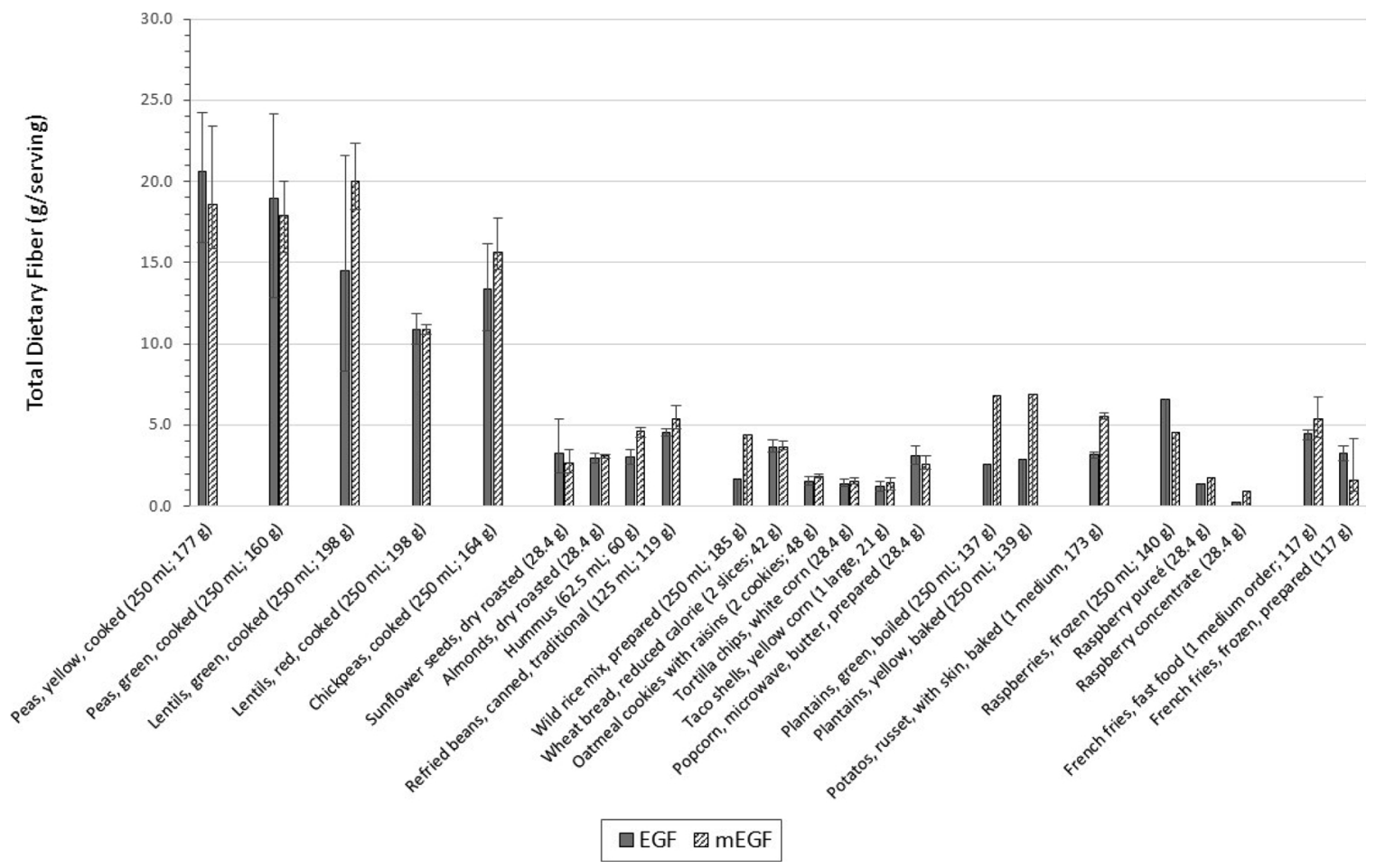

Fig. 5. Mean total dietary fiber content per serving of foods as consumed, measured by traditional enzymatic-gravimetric analysis of total dietary fiber (EGF) (method 985.29; AOAC, 2005b) and the modified enzymatic-gravimetric method (mEGF) introduced in 2009 (methods 2009.01 and 2011.25; AOAC, 2011, 2012). [250 mL dry measure = 1 cup; serving sizes from USDA Legacy Food Composition Database (Haytowitz et al., 2018) and/or measured in this study.

the same "food" (e.g., "dry roasted sunflower seed kernels" or "cooked lentils") could result in different fiber content or content measured by the different enzymatic-gravimetric methods. It is therefore useful to look at the food mean total dietary fiber in the foods as consumed, and per typical serving size, to assess the potential impact of changing dietary fiber values. In just the foods in this study, mean mEGF dietary fiber ranged from -2.0 to $+5.5 \mathrm{~g} /$ serving relative to EGF (Fig. 5). These differences are nutritionally meaningful and can change population-based estimates of intake and adequacy of dietary fiber, for which the median U.S. daily intake has been estimated to be $12-14 \mathrm{~g}$ compared to the recommended 28-42 g (Thompson and Brick, 2016).

However, the high analytical variability (Tables 4 and 5) and wide range in assayed fiber content by both methods among samples of the same food led to no statistically significant difference between EGF and mEGF in some foods, for which a difference might be expected. For example, EGF ranged from 8.0 to 15.1 and mEGF from 9.8 to $12.5 \mathrm{~g} /$ $100 \mathrm{~g}$ among three samples of cooked green peas. Considering a serving size of $160 \mathrm{~g}$ ( $250 \mathrm{~mL} ; 1 \mathrm{cup}$ ), there is an overall range of more than $11 \mathrm{~g} /$ serving, nearly half of a $25 \mathrm{~g} /$ day total dietary fiber intake. However, it is reasonable to expect, based on the composition of those foods, that there may be a nutritionally meaningful amount of resistant starch or non-digestible oligosaccharides that could vary widely based on variation in method of preparation (Dhingra et al., 2012; Liu et al., 1993). The lack of replicate analyses of individual samples in this study preclude separation of analytical variability from sample-to-sample variability on a food by food basis, but the MDDs of up to $3.7 \mathrm{~g} / 100 \mathrm{~g}$ (Table 5) provide some estimate of the overall difference that could be detected beyond analytical uncertainty (aside from any sample-tosample differences in composition). On the other hand, the statistically significant differences in EGF and mEGF in some foods were not impactful when typical serving size is considered. For example, the $2.2 \mathrm{~g} /$ $100 \mathrm{~g}$ difference in sunflower seeds amounts to only $0.6 \mathrm{~g}$ per $28.4 \mathrm{~g}$ serving.

These observations suggest caution is advisable in interpreting differences in food mean values that are not based on robust sampling, along with informed consideration of food preparation and methodological factors that can affect the fiber composition and analytical accuracy and precision (Sections. 4.1.2-4.1.4) and the expected dietary contribution should be contemplated when prioritizing foods for analysis. The high cost of these assays adds to the need to prioritize foods. Based on the results of this study, there would be no point in trying to measure food mean differences in dietary fiber by the traditional or modified enzymatic-gravimetric methods in cooked dried pulses, wheat bread, tortilla chips or prepared rice, and resources would be wasted on foods like nuts and seeds (unless there was a particularly high intake in a given population or study).

\section{Conclusions}

More and better data are needed to assure us that claiming that fiber is a shortfall nutrient is based on the best evidence possible. Improvements to methodology and databases on the content and composition of fiber in food, and education of those using the data on the challenges of reconciling estimates of fiber intake taken years apart and based on different measurement systems are necessary. Dietary fiber methodology has barely changed in the last three decades. The presence of resistant starch and prebiotic oligosaccharides in foods, as potential "dietary fiber" has been recognized since at least the 1980s (for example, Berry, 1986; Dreher et al., 1984; Fleming et al., 1988; Ring et al., 1988), yet recent modifications to the traditional enzymaticgravimetric assay have not changed the basic methodology.

Prioritizing foods that need to be analyzed using methodology consistent with the current definition of dietary fiber is also important. Data for dietary fiber in U.S. foods, for example in USDA Legacy SR database (Haytowitz et al., 2018), are currently based on the traditional EGF assay. The mEGF assay can cost more than three times as much as the EGF assay. Insight from this study can help inform decisions on which foods to prioritize, based on whether a measurable (and nutritionally meaningful) difference would be expected, or whether the food contains dietary fiber components that are of research interest for 
Table 7

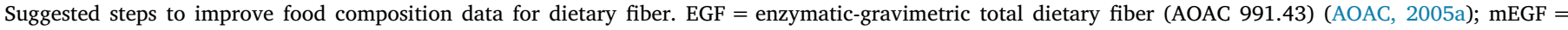
modified enzymatic-gravimetric total dietary fiber (AOAC 2009.01, 2011.25) (AOAC, 2011, 2012).

Improve existing enzymatic-gravimetric methodology

Ensure analytical method does not alter dietary fiber in the food as consumed

Implement quality control measures

Generate better food composition data

Prioritize foods for updated analysis of dietary fiber

Generate database of biologically active chemical compounds, not just "dietary fiber" in foods

Retain historical dietary fiber data in food composition databases

Educate users of food composition data
- Sample size: Adjust weight of undried samples so that solids are at least $1 \mathrm{~g}$, and reduce buffer volume proportionally.

- Filtering crucibles: Use smaller or lighter weight crucibles to maximize the difference in tare weight and weight including fiber residue

- Assay of residual protein: Replace Kjeldahl nitrogen assay with a more direct approach to determining residual protein

- Direct assay of non-digestible oligosaccharides in sample, not in supernatant from fiber assay, optimizing sample size and assay parameters to decrease the limit of quantitation

- Find ways to reduce the cost and labor intensity of the analysis

- Eliminate freezing and freeze-drying of foods

- Consider whether grinding is representative of digestibility food as consumed

- Consider bioavailability and functionality of fiber components and whether current in vitro assay parameters reflect current knowledge about in vivo digestion

- Include control material of matrix similar in proximate and dietary fiber content and composition in each analytical batch

- Develop more certified reference materials, representing foods with a wider range of fiber content and composition

- Develop and implement inter-laboratory control materials to enable a cost effective and objective comparison of data across laboratories, methods, and time ${ }^{\text {a }}$

- Account for differences in dietary fiber content and composition in a given food resulting from different food preparation and processing methods

- Do not assume fiber content of ingredients in processed foods are additive based on the composition of the unprocessed ingredients (particularly for high starch foods)

- Consider sources of variability in dietary fiber content when sampling foods (e.g. cultivar, maturity, postharvest storage or processing)

- Ensure that number of samples and sampling plan takes into account expected sources of variability

- Harmonize methods for starch, proximates, and dietary fiber so that some components of dietary fiber are not double counted (de Menezes et al., 2016d; Haytowitz and Phillips, 2017)

- Select foods that are major contributors to fiber intake

- Are data for raw foods that are not consumed raw (e.g. potatoes, dried legumes)?

- Select foods that contain components not quantified by EGF, estimate the expected difference, and determine whether it would be large enough to be nutritionally meaningful, and to exceed analytical uncertainty (If no difference or no measurable difference is expected, use EGF or mEGF without the LMWSDF assay, due to lower cost.)

- Analyze each class of compounds [e.g. beta glucan, chitin, oligosaccharides, resistant starch and different types of resistant starch (Ma and Boye, 2018), pectin, cellulose] in separate assays of the sample, optimized for quantitative analysis and limits of detection and quantitation

- Instead of replacing "dietary fiber", define new data field for dietary fiber based on methodology

- Educated users of data on changing values and definition of "dietary fiber" in food composition databases, in particular those linked to estimation of dietary intake in epidemiological studies

- About the uncertainties and effect of changing methodology on values and interpretation of studies on dietary fiber intake and health outcomes and comparing studies at different points in time

- How values for "dietary fiber" are defined by methodology and have changed and may continue to change due to methodology, not change in food intake when

- About variability and caution in using food mean values to calculate intake

- About the magnitude of analytical uncertainty in enzymatic-gravimetric dietary fiber values, that must be accounted for when comparing data for different samples and/or from different laboratories to avoid attributing analytical differences to biodiversity a e.g. as described in Phillips and Rasor (2016).

particular biological effects or health outcomes (e.g., resistant starch, prebiotic oligosaccharides, beta-glucans). Also, more attention must be paid to the effect of processing on dietary fiber content and composition. For example, different variations of cooking, canning, baking, drying, extruding and other processes can have significant and variable effects on different dietary fiber components, and total dietary fiber content. Thus, the content and functionality of fiber as consumed may not be possible to accurately estimate in a formulated product by simply adding together the fiber contents of each ingredient. As the understanding of the role of "fiber" in health beyond contributing to intestinal motility has increased, the need for more refined food composition data for specific components, not just "dietary fiber", is critical to support observational and prospective studies, and to inform dietary recommendations, as also advocated by other researchers (Englyst et al., 2007; Fuller et al., 2018; Macagnan et al., 2016). A number of improvements could be made to increase precision and accuracy in the measurement of dietary fiber in foods, and to enhance data for dietary fiber in food composition databases (see Table 7). Yet, new values for dietary fiber generated by different methodology should not simply replace previous values; rather additional identification codes should be assigned to total dietary fiber as defined by method of analysis, and for individual dietary fiber components.

\section{Disclaimer}

Reference to any product, service, process, or method by trade name, trademark, service mark, manufacturer or otherwise is for ease of identification only and does not imply recommendation, endorsement, or approval by, or an association with, the U.S. Department of Agriculture, Virginia Tech, or any of the authors.

\section{Declaration of Competing Interest}

None.

\section{Acknowledgments}

This work was supported by cooperative agreements59-8040-8-005, 60-8040-6-011 and 60-8040-8-005 between the USDA Agricultural Research Service Nutrient Data Laboratory and Virginia Tech 
(including funds from interagency agreements between USDA and the National Cancer Institute and the Food and Drug Administration, the American Pulse Association (agreement \#15-1435-01), and the National Processed Raspberry Council (agreement \# 8040-05-25 0057704). Amy Rasor, Nancy Conley, and Ryan McGinty assisted with sample preparation.

\section{Appendix A. Supplementary data}

Supplementary material related to this article can be found, in the online version, at doi:https://doi.org/10.1016/j.jfca.2019.103253.

\section{References}

Ahuja, J.K., Goldman, J.D., Perloff, B.P., 2006. The effect of improved food composition data on intake estimates in the United States of America. J. Food Compos. Anal. 19, S7-S13.

Ahuja, J.K., Moshfegh, A.J., Holden, J.M., Harris, E., 2012. USDA food and nutrient databases provide the infrastructure for food and nutrition research, policy, and practice, 2. J. Nutr. 143 (2), 241S-249S.

Aldwairji, M.A., Chu, J., Burley, V.J., Orfila, C., 2014. Analysis of dietary fibre of boiled and canned legumes commonly consumed in the United Kingdom. J. Food Compos. Anal. 36, 111-116.

Anderson, J.W., 1985. Physiological and metabolic effects of dietary fiber. Fed. Proc. 44, 2902-2906.

Anderson, J.W., Baird, P., Davis Jr, R.H., Ferreri, S., Knudtson, M., Koraym, A., Waters, V., Williams, C.L., 2009. Health benefits of dietary fiber. Nutr. Rev. 67, 188-205.

AOAC, 2005a. Total, soluble, and insoluble dietary fiber in foods, Enzymatic-gravimetric method, MES-TRIS buffer. official method 991.43 (32.1.17). AOAC Official Methods of Analysis. Association of Official Analytical Chemists International., Gaithersburg, MD, USA.

AOAC, 2005b. Total dietary fiber in foods - enzymatic-gravimetric method. Official method 985.29 (45.4.07). AOAC Official Methods of Analysis. Association of Official Analytical Chemists International., Gaithersburg, MD, USA.

AOAC, 2011. Insoluble, soluble, and total dietary fiber in foods enzymatic-gravimetric-liquid chromatography. official method 2011.25 (32.1.43). AOAC Official Methods of Analysis. Association of Official Analytical Chemists International, Gaithersburg, MD, USA.

AOAC, 2012. Total dietary fiber in foods enzymatic-gravimetric-liquid chromatographic method. official method 2009.01 (45.4.17). AOAC Official Methods of Analysis. Association of Official Analytical Chemists International, Gaithersburg, MD, USA.

Asp, N.G., Johansson, C.-G., Hallmer, H., Siljeström, M., 1983. Rapid enzymatic assay of insoluble and soluble dietary fiber. J. Agric. Food Chem. 31, 476-482.

Atwater, W.O., Woods, C.D., 1896. The Chemical Composition of American Food Materials. Bulletin No. 28 Retrieved February 25, 2019 from. U.S. Department of Agriculture, Beltsville, MD, USA. https://www.ars.usda.gov/ARSUserFiles/ 80400525/Data/Classics/es028.pdf.

Baker, D., Norris, K.H., Li, B.W., 1979. Food fiber analysis: advances in methodology. In: Inglett, G.E., Falkehag, S.I. (Eds.), Dietary Fibers: Chemistry and Nutrition. Academic Press, New York, NY, USA, pp. 67-78.

Bazzano, L.A., He, J., Ogden, L.G., Loria, C.M., Whelton, P.K., 2003. Dietary fiber intake and reduced risk of coronary heart disease in US men and women: the National Health and Nutrition Examination Survey I Epidemiologic Follow-up Study. Arch. Intern. Med. 163, 1897-1904.

Berry, C., 1986. Resistant starch: formation and measurement of starch that survives exhaustive digestion with amylolytic enzymes during the determination of dietary fibre. J. Cereal Sci. 4, 301-314.

Bodner-Montville, J., Ahuja, J.K., Ingwersen, L.A., Haggerty, E.S., Enns, C.W., Perloff, B.P., 2006. USDA food and nutrient database for dietary studies: released on the web. J. Food Compos. Anal. 19, S100-S107.

Brummer, Y., Kaviani, M., Tosh, S.M., 2015. Structural and functional characteristics of dietary fibre in beans, lentils, peas and chickpeas. Food Res. Int. 67, 117-125.

Buil-Cosiales, P., Toledo, E., Salas-Salvadó, J., Zazpe, I., Farràs, M., Basterra-Gortari, F.J., Diez-Espino, J., Estruch, R., Corella, D., Ros, E., Marti, A., 2016. Association between dietary fibre intake and fruit, vegetable or whole-grain consumption and the risk of CVD: results from the PREvencion con DIeta MEDiterranea (PREDIMED) trial. Br. J. Nutr. 116, 534-546.

Centers for Disease Control and Prevention, 2007. National Health and Nutrition Examination Survey, What We Eat in America. Hyattsville. Retrieved October 17, 2018 from:. US Department of Health and Human Services, Centers for Disease Control and Prevention, MD, USA. https://www.cdc.gov/nchs/nhanes/wweia.htm.

Champagne, C.M., Pehrsson, P.R., Haytowitz, D.B., 2019. Food composition data and databases. In: Van Horn, L., Beto, J. (Eds.), Research: Successful Approaches in Nutrition and Dietetics, 4th ed. Academy of Nutrition and Dietetics, Chicago, IL, USA (in press).

Chen, Y., McGee, R., Vandemark, G., Brick, M., Thompson, H.J., 2016. Dietary fiber analysis of four pulses using AOAC 2011.25: implications for human health. Nutrients 8 (12), 829. Retrieved March 5, 2019 from: https://www.ncbi.nlm.nih.gov/pmc/ articles/PMC5188482/.

Chiavaroli, L., Mirrahimi, A., Sievenpiper, J.L., Jenkins, D.J.A., Darling, P.B., 2015. Dietary fiber effects in chronic kidney disease: a systematic review and meta-analysis of controlled feeding trials. Eur. J. Clin. Nutr. 69, 761-768.

Code of Federal Regulations, 2018. Food Labeling. 21CFR101.9, Sections (g)(8)-(10), April 1, 2018. Retrieved February 14, 2019 from:. https://www.accessdata.fda. gov/scripts/cdrh/cfdocs/cfcfr/CFRSearch.cfm?fr =101.9\&SearchTerm = nutrition $\% 20$ label.

Codex Alimentarius, 2009. Report of the 31st Session of the Codex Committee on Nutrition and Foods for Special Dietary Uses. November 2-6, 2009 Retrieved January 3, 2019 from. ALINORM 10/33/26, Düsseldorf, Germany. https://www. google. $\mathrm{com} / \mathrm{url}$ ? sa $=\mathrm{t} \& \mathrm{rct}=\mathrm{j} \& \mathrm{q}=\& \mathrm{esrc}=\mathrm{s} \&$ source $=$ web\&cd $=2 \& \mathrm{ved}=$ 2ahUKEwj76v7XsNLfAhXtzVkKHcfXDekQFjABegQICRAC\&url = http\%3A\%2F \%2Fwww.fao.org\%2Ftempref\%2Fcodex $\% 2$ FReports\%2FAlinorm $10 \% 2$ Fal33_26e.pdf \&usg = AOvVaw3YC1N9gACNfYKQL4mkIess.

Cranker, K.J., Phillips, K.M., Gonzales, M.C., Stewart, K.K., 1997. Effect of seeds on bileenzymatic-gravimetric analysis of total dietary fiber. J. AOAC. Int. 80, 89-94.

Cummings, J.H., 1976. What is fiber? In: Spiller, G.A., Amen, R.J. (Eds.), Fiber in Human Nutrition. Plenum Press, New York, NY, USA, pp. 1-30.

Dahl, W.J., Stewart, M.L., 2015. Position of the Academy of Nutrition and Dietetics: health implications of dietary fiber. J. Acad. Nutr. Diet. 115, 1861-1870.

Dai, F.-J., Chau, C.-F., 2017. Classification and regulatory perspectives of dietary fiber. J. Food Drug Anal. 25, 37-42.

Dai, Z., Niu, J., Zhang, Y., Jacques, P., Felson, D.T., 2017. Dietary intake of fibre and risk of knee osteoarthritis in two US prospective cohorts. Ann. Rheum. Dis. 76, 1411-1419.

de Menezes, E.W., Giuntini, E.B., Dan, M.C.T., Sardá, F.A.H., Lajolo, F.M., 2013. Codex dietary fibre definition-Justification for inclusion of carbohydrates from 3 to 9 degrees of polymerisation. Food Chem. 140, 581-585.

de Menezes, E.W., Grande, F., Giuntini, E.B., do Vale, T., Lopes, T.V.C., Dan, M.C.T., Ramos do Prado, S.B., de Melo Franco, B.D.G., Charrondière, U.R., Lajolo, F.M., 2016d. Impact of dietary fiber energy on the calculation of food total energy value in the Brazilian Food Composition Database. Food Chem. 193, 128-133.

Dhingra, D., Michael, M., Rajput, H., Patil, R., 2012. Dietary fibre in foods: a review. J. Food Sci. Technol. 49, 255-266.

Englyst, K., Liu, S., Englyst, H., 2007. Nutritional characterization and measurement of dietary carbohydrates. Eur. J. Clin. Nutr. 61, S19-S39.

Fan, P.H., Zang, M.T., Xing, J., 2015. Oligosaccharides composition in eight food legumes species as detected by high-resolution mass spectrometry. J. Sci. Food Agric. 95, 2228-2236.

Fleming, S.E., Fitch, M.D., Stanley, D.W., 1988. Influence of processing on physical form of beans and on intestinal fermentation. J. Food Sci. 53, 777-782.

Food Standards Australia New Zealand, 2017. Assessment of Resistant Starch As Dietary Fibre; and Suitability of AOAC 2002.02 As a Regulatory Method of Analysis: Addition of a Prescribed Method of Analysis for Resistant Starch. Application A1142. Retrieved December 3. 2018 from:. https://www.google.com $/$ url? sa $=t \& r c t=j \& q=\&$ esrc $=s \&$ source $=$ web\&cd $=5 \&$ ved $=2$ ahUKEwj8

8nf3oTfAhXQmeAKHQyxBosQFjAEegQIBRAC\&url = https\%3A\%2F\%2Fwww foodstandards.gov.au\%2Fcode\%2Fapplications\%2FDocuments\%2FA1142\%2520RS $\% 2520$ SD1.pdf\&usg = AOvVaw0dH SgRv-Hun1CHtbOthp4.

Fuentes-Zaragoza, E., Sánchez-Zapata, E., Sendra, E., Sayas, E., Navarro, C., Fernández-López, J., Pérez-Alvarez, J.A., 2011. Resistant starch as prebiotic: a review. StarchStrke 63 (7), 406-415.

Fujihara, S., Kasuga, A., Aoyagi, Y., 2001. Nitrogen-to-protein conversion factors for common vegetables in Japan. Food Chemistry and Toxicology 66, 412-415.

Fuller, S., Tapsell, L.C., Beck, E.J., 2018. Creation of a fibre categories database to quantify different dietary fibres. J. Food Compos. Anal. 71, 36-43.

Greenfield, H., Southgate, D.A.T., 2003. Food Composition Data: Production, Management, and Use, $2^{\text {nd }}$ ed. Food and Agriculture Organization of the United Nations, Rome, Italy.

Grootaert, C., Delcour, J.A., Courtin, C.M., Broekaert, W.F., Verstraete, W., Van de Wiele, T., 2007. Microbial metabolism and prebiotic potency of arabinoxylan oligosaccharides in the human intestine. Trends Food Sci. Technol. 18 (2), 64-71.

Harvard, T.H., 2018. Health Professionals Follow-Up Study. Retrieved October 17, 2018 from. Chan School of Public Health, Boston, MA, USA. https://sites.sph.harvard.edu/ hpfs/.

Haytowitz, D.B., Klensin, J.C., 1994. Electronic dissemination of nutrient data via bulletin boards and internet. Proceedings of the 17th National Nutrient Data Bank Conference, Baltimore, Maryland. pp. 293-305 June 7-10, 1992.

Haytowitz, D.B., Pehrsson, P.R., Holden, J.M., 2008. The national food and analysis program: a decade of progress. J. Food Compos. Anal. 21, S94-S102.

Haytowitz, D.B., Pehrsson, P.R., 2018. USDA's National Food and Nutrient Analysis Program (NFNAP) produces high-quality data for USDA food composition databases: two decades of collaboration. Food Chem. 238, 134-138.

Haytowitz, D.B., Phillips, K.M., 2017. Comparing fiber methods in calculating carbohydrates by summation - issues with carbohydrate fractions. 11th Vahouny Fiber Symposium June 15-16, 2017.

Haytowitz, D.B., Ahuja, J.K., Khan, M., Somanchi, M., Nickle, M.S., Ngyuen, Q.A., Roseland, J.M., Williams, J.R., Patterson, K., Li, Y., Perhsson, P.R., 2018. USDA National Nutrient Database for Standard Reference - Legacy. Retrieved December 26, 2018 from. https://ndb.nal.usda.gov.

Hollmann, J., Themeier, H., Neese, U., Lindhauer, M.G., 2013. Dietary fibre fractions in cereal foods measured by a new integrated AOAC method. Food Chem. 140, $586-589$.

Horwitz, W., Albert, R., 2006. The Horwitz ratio (HorRat): a useful index of method performance with respect to precision. J. AOAC. Int. 89, 1095-1109.

Institute of Medicine, 2001. Dietary Reference Intakes: Proposed Definition of Dietary Fiber. The National Academies Press, Washington, DC, USA. https://doi.org/10. 17226/10161. 
Jones, D.B., 1931. Factors for Converting Percentages of Nitrogen in Foods and Feeds Into Percentages of Proteins. Circ No.183. U.S. Department of Agriculture, Washington, DC, USA.

Jones, J.M., 2004. Dietary fiber intake, disease prevention, and health promotion: an overview with emphasis on evidence from epidemiology. In: van der Kamp, J.W., Asp, N.G., Miller-Jones, J., Schaafsma, G. (Eds.), Bioactive Carbohydrates for Food and Feed. Netherlands: Academic Publishers, pp. 143-164.

Jones, J.M., 2014. CODEX-aligned dietary fiber definitions help to bridge the 'fiber gap' Nutr. J. 13, 34.

Kleintop, A.E., Echeverria, D., Brick, L.A., Thompson, H.J., Brick, M.A., 2013. Adaptation of the AOAC 2011.25 integrated total dietary fiber assay to determine the dietary fiber and oligosaccharide content of dry edible beans. J. Agric. Food Chem. 61, 9719-9726.

Kuijsten, A., Aune, D., Schulze, M.B., Norat, T., van Woudenbergh, G.J., Beulens, J.W., Sluijs, I., Spijkerman, A.M., van der, A.D.L., Palli, D., Kühn, T., Wendt, A., Buijsse, B., Boeing, H., Pala, V., Amiano, P., Buckland, G., Huerta, J.M., Tjøonneland, A., Kyrø, C., Redondo, M.L., Sacerdote, C., Sánchez, M.J., Fagherazzi, G., Balkau, B., et al., 2015. Dietary fibre and incidence of type 2 diabetes in eight European countries: the EPIC-InterAct Study and a meta-analysis of prospective studies. Diabetologia 58, 1394-1408.

Li, B.W., Schuhmann, P.J., Wolf, W.R., 1985. Chromatographic determinations of sugars and starch in a diet composite reference material. J. Agric. Food Chem. 33, 531-536.

Liu, K., Phillips, R.D., McWatters, K.H., 1993. Mechanism of pectin changes during soaking and heating as related to hard-to-cook defect in cowpeas. J. Agric. Food Chem. 41, 1476-1480.

Ma, Z., Boye, J.I., 2018. Research advances on structural characterization of resistant starch and its structure-physiological function relationship: a review. Crit. Rev. Food Sci. Nutr. 58, 1059-1083.

Macagnan, F.T., da Silva, L.P., Hecktheuer, L.H., 2016. Dietary fibre: the scientific search for an ideal definition and methodology of analysis, and its physiological importance as a carrier of bioactive compounds. Food Res. Int. 85, 144-154.

Maningat, C.C., Seib, P.A., Bassi, S.D., 2013. Recovery of resistant starch by a classical and a new assay for dietary fiber. Cereal Chem. 90, 515-516.

McCleary, B.V., 2010. Development of an integrated total dietary fiber method consistent with the Codex Alimentarius definition. Cereal Foods World 55, 24-28.

McCleary, B.V., 2014. Modification to AOAC official methods 2009.01 and 2011.25 to allow for minor overestimation of low molecular weight soluble dietary fiber in samples containing starch. J. AOAC. Int. 97, 896-901.

McCleary, B.V., De Vries, J.W., Rader, J.I., Cohen, G., Prosky, L., Mugford, D.C., Champ, M., Okuma, K., 2010. Determination of total dietary fiber (CODEX definition) by enzymatic-gravimetric method and liquid chromatography: collaborative study. J. AOAC. Int. 93, 221-233.

McCleary, B.V., DeVries, J.W., Rader, J.I., Cohen, G., Prosky, L., Mugford, D.C., Champ, M., Okuma, K., 2012. Determination of insoluble, soluble, and total dietary fiber (CODEX definition) by enzymatic-gravimetric method and liquid chromatography: collaborative study. J. AOAC. Int. 95, 824-844.

McCleary, B.V., Sloane, N., Draga, A., Lazewska, I., 2013. Measurement of total dietary fiber using AOAC method 2009.01 (AACC International mpproved Method 32-45.01): evaluation and updates. Cereal Chem. 90, 396-414.

Menoli, A.V., Beleia, A., 2007. Starch and pectin solubilization and texture modification during pre-cooking and cooking of cassava root (Manihot esculenta Crantz). LWT-Food Science and Technology 40, 744-747.

Mussatto, S.I., Mancilha, I.M., 2007. Non-digestible oligosaccharides: a review. Carbohydr. Polym. 68, 587-597.

NIST, 2014. Certificate of Analysis for Standard Reference Material ${ }^{\circledR} 3233$ Fortified Breakfast Cereal. Retrieved October 4, 2018 from:. National Institute of Standards and Technology, Gaithersburg, MD, USA. https://www-s.nist.gov/srmors/view_cert. $\mathrm{cfm} ? \mathrm{srm}=3233$.

NIST, 2015. Certificate of Analysis for Standard Reference Material ${ }^{\varpi} 2387$ Peanut Butter. Retrieved October 4, 2018 from:. https://www-s.nist.gov/srmors/view_cert.cfm? $\mathrm{srm}=2387$.

Nutrition Labeling and Education Act, 1990. Public Law 101-535, 104 Stat 2353, Sec. 2(b). Retrieved February 9, 2019 from:. Government Printing Office DC, Washington, DC, USA. https://www.govinfo.gov/content/pkg/STATUTE-104/pdf/ STATUTE-104-Pg2353.pdf.

Ott, R.L., Longnecker, M.T., 2016. An Introduction to Statistical Methods and Data Analysis. Cengage Learning, Boston, MA, USA.

Pastell, H., Putkonen, T., 2014. New Dietary Fibre Content Results of Cereal, Vegetable and Fruit Samples. Retrieved December 3, 2018 from:. Finnish Food Safety Authority Evira, Helsinki, Finland. https://www.google.com/url?sa $=t \& r c t=j \& q=\&$ esrc $=$ s\&source $=$ web\&cd $=1 \& \mathrm{cad}=$ rja\&uact $=8 \& \mathrm{ved}=$ 2ahUKEwj087Lf4oTfAhVFrVkKHf02CW0QFjAAegQICRAB\&url = https\%3A\%2F \%2Fwww.researchgate.net\%2Fpublication\%2F271732454_New_dietary_fibre content_results_of_cereal_vegetable_and_fruit_samples\&usg = AOVVaw3 wwSX3o2YemL9RH0M0gHn.

Pehrsson, P.R., Perry, C., Daniels, M., 2013. ARS, USDA updates food sampling strategies to keep pace with demographic shifts. Procedia Food Sci. 2, 52-59.

Pehrsson, P.R., Haytowitz, D.B., 2016. Food composition databases. In: Caballero, B., Finglas, P.M., Toldrá, F. (Eds.), Encyclopedia of Food and Health. Elsevier, New York, NY, USA, pp. 16-21.

Perera, A., Meda, V., Tyler, R.T., 2010. Resistant starch: a review of analytical protocols for determining resistant starch and of factors affecting the resistant starch content of foods. Food Res. Int. 43, 1959-1974.

Phillips, K.M., Palmer, J.K., 1991. Effect of freeze-drying and heating during analysis on dietary fiber in cooked and raw carrots. J. Agric. Food Chem. 39, 1216-1221.

Phillips, K.M., Patterson, K.Y., Rasor, A.R., Exler, J., Haytowitz, D.B., Holden, J.M.,
Pehrsson, P.R., 2006. The role of quality control and reference materials in the National Food and Nutrient Analysis Program. Anal. Bioanal. Chem. 384, 1341-1355.

Phillips, K.M., Rasor, A.S., 2016. A mixed mushroom control material to facilitate interlaboratory harmonization of mushroom composition analyses. J. Food Compos. Anal. 48, 48-66.

Plat, D., Ben-Shalom, N., Levi, A., Reid, D., Goldschmidt, E.E., 1988. Degradation of pectic substance in carrots by heat treatment. J. Agric. Food Chem. 36, 362-365.

Qi, B., Moore, K.G., Orchard, J., 2000. A comparison of two methods and the effect of cooking time on the extractability of pectin from the cell walls of cooking banana. LWT-Food Science and Technology 33, 369-373.

Raatz, S.K., Idso, L., Johnson, L.K., Jackson, M.I., Combs, G.F., 2016. Resistant starch analysis of commonly consumed potatoes: content varies by cooking method and service temperature but not by variety. Food Chem. 208, 297-300.

Raigond, P., Ezekiel, R., Raigond, B., 2015. Resistant starch in food: a review. J. Sci. Food Agric. 95, 1968-1978.

Ralet, M.C., Thibault, J.F., Della Valle, G., 1991. Solubilization of sugar-beet pulp cell wall polysaccharides by extrusion-cooking. Lebensmittel Wissenschaft und Technologie 24, 107-112.

Ring, S.G., Gee, J.M., Whittam, M., Orford, P., Johnson, I.T., 1988. Resistant starch: Its chemical form in foodstuffs and effect on digestibilityin vitro. Food Chem. 28, 97-109.

Roberfroid, M.B., 2005. Introducing inulin-type fructans. Br. J. Nutr. 93, S13-S25.

Salmas, G., DeVries, J., Plank, D., 2017. Challenges for dietary fiber: benefits and costs of new US Regulations. Cereal Foods World 62 (3), 88-94.

Soares, C.A., Peroni-Okita, F.H.C., Cardoso, M.B., Shitakubo, R., Lajolo, F.M., Cordenunsi, B.R., 2011. Plantain and banana starches: granule structural characteristics explain the differences in their starch degradation patterns. J. Agric. Food Chem. 59 6672-6681.

Southgate, D.A.T., 1976. The analysis of dietary fiber. In: Spiller, G.A., Amen, R.J. (Eds.), Fiber in Human Nutrition. Plenum Press, New York, NY, USA, pp. 73-107.

Stephen, A.M., Champ, M.M.-J., Cloran, S.J., Fleith, M., Van Lieshout, L., Mejborn, H., Burley, V.J., 2017. Dietary fibre in Europe: current state of knowledge on definitions, sources, recommendations, intakes and relationships to health. Nutr. Res. Rev. 30, 149-190.

Story, J.A., Kritchevsky, D., Eastwood, M.A., 1979. Dietary fiber - bile acid interactions. In: Inglett, G.E., Falkehag, S.I. (Eds.), Dietary Fibers: Chemistry and Nutrition. Academic Press, New York, NY, USA, pp. 49-55.

Swennen, I., Courtin, C.M., Delcour, J.A., 2006. Non-digestible oligosaccharides with prebiotic properties. Crit. Rev. Food Sci. Nutr. 46, 459-471.

Thakur, B.R., Singh, R.K., Handa, A.K., Rao, M.A., 1997. Chemistry and uses of pectin—a review. Crit. Rev. Food Sci. Nutr. 37, 47-73.

Theander, O., James, P., 1979. European efforts in dietary fiber characterization. In: Inglett, G.E., Falkehag, S.I. (Eds.), Dietary Fibers: Chemistry and Nutrition. Academic Press, New York, NY, USA, pp. 245-249.

Thompson, H.J., Brick, M.A., 2016. Perspective: closing the dietary fiber gap: an ancient solution for a 21st century problem. Adv. Nutr. 7, 623-626.

Tobaruela, E.C., Santos, A.O., Almeida-Muradian, L.B., Araujo, E.S., Lajolo, F.M., Menezes, E.W., 2018. Application of dietary fiber method AOAC 2011.25 in fruit and comparison with AOAC 991.43 method. Food Chem. 238, 87-93.

Trainer, D., Pehrsson, P.R., Haytowitz, D.B., Holden, J.M., Phillips, K.M., Rasor, A.S., Conley, N.A., 2010. Development of sample handling procedures under USDA's National Food and Nutrient Analysis Program. J. Food Compos. Anal. 23, 843-851.

University of Minnesota, Nutrition Coordinating Center, 2018. Nutrition Data System for Research (NDSR). Retrieved October 17, 2018 from:. University of Minnesota, Nutrition Coordinating Center, Minneapolis, MN, USA. www.ncc.umn.edu/ products/.

U.S. Department of Agriculture USDA's Agriculture, 1990. Composition of Foods: Raw, Processed, Prepared, Handbook No. 8 (1950- 1990)Retrieved November 15, 2018 from:. United States Agricultural Research Service Consumer and Food Economics Research Division. Legacy versions. https://naldc-legacy.nal.usda.gov/naldc/search. xhtml.

U.S. Department of Agriculture, Agricultural Research Service, 2016. USDA National Nutrient Database for Standard Reference. Release 28. Retrieved March 5, 2017 from. http://www.nal.usda.gov/fnic/foodcomp/search/.

U.S. Department of Agriculture, Agricultural Research Service, Nutrient Data Laboratory, 2018. USDA National Nutrient Database for Standard Reference. Releases 1-28 and Legacy. 1980-2018. Retrieved February 8, 2019 from. https://www.ars.usda.gov/ northeast-area/beltsville-md-bhnrc/beltsville-human-nutrition-research-center/ nutrient-data-laboratory/docs/usda-national-nutrient-database-for-standardreference/.

U.S. Department of Agriculture, Agricultural Research Service, 2019. FoodData Central. www.fdc.nal.usda.gov.

U.S. Food and Drug Administration, Office of Regulatory Affairs, 1994. Guide to Nutrition Labeling and Education Act (NLEA) Requirements. Retrieved February 9, 2019 from. https://web.archive.org/web/20071014014547/http://www.fda.gov/ora/inspect ref/igs/nleatxt.html.

U.S. Food and Drug Administration, 2016. Food Labeling: Revision of the Nutrition and Supplement Facts Labels. May 27, 2016. Retrieved March 7, 2019 from:. Office of the Federal Register, Washington, DC, USA. https://www.federalregister.gov/ documents/2016/05/27/2016-11867/food-labeling-revision-of-the-nutrition-andsupplement-facts-labels.

U.S. Food and Drug Administration, 2018. The Declaration of Certain Isolated or Synthetic Non-digestible Carbohydrates As Dietary Fiber on Nutrition and Supplement Facts Labels: Guidance for Industry. Retrieved October 16, 2018 from:. Office of Nutrition and Food Labeling in the Center for Food Safety and Applied Nutrition, College Park, MD, USA. https://www.fda.gov/downloads/Food/ 
GuidanceRegulation/GuidanceDocumentsRegulatoryInformation/UCM610144.pdf. Van Buren, J.P., 1986. Snap bean texture softening and pectin solubilization caused by the presence of salt during cooking. J. Food Sci. 51 (1), 131-134.

Van Soest, P.J., 1978. Dietary fibers: their definition and nutritional properties. Am. J. Clin. Nutr. 31, S12-S20.

Van Soest, P.J., Robertson, J.B., Lewis, B.A., 1991. Methods for dietary fiber, neutral detergent fiber, and nonstarch polysaccharides in relation to animal nutrition. J. Dairy Sci. 74, 3583-3597.

Veronese, N., Solmi, M., Caruso, M.G., Giannelli, G., Osella, A.R., Evangelou, E., Maggi, S., Fontana, L., Stubbs, B., Tzoulaki, I., 2018. Dietary fiber and health outcomes: an umbrella review of systematic reviews and meta-analyses. Am. J. Clin. Nutr. 107, 436-444.
Westenbrink, S., Brunt, K., van der Kamp, J.-W., 2013. Dietary fibre: challenges in production and use of food composition data. Food Chem. 140, 562-567.

Wu, Y., Qian, Y., Pan, Y., Li, P., Yang, J., Ye, X., Xu, G., 2015. Association between dietary fiber intake and risk of coronary heart disease: a meta-analysis. Clin. Nutr. 34, 603-611.

Yang, Y., Zhao, L.G., Wu, Q.J., Ma, X., Xiang, Y.B., 2015. Association between dietary fiber and lower risk of all-cause mortality: a meta-analysis of cohort studies. Am. J. Epidemiol. 181 (2), 83-91.

Zielinski, G., DeVries, J.W., Craig, S.A., Bridges, A.R., 2013. Dietary fiber methods in Codex Alimentarius: current status and ongoing discussions. Cereal Foods World 58 (3), 148-152. 